\title{
Cash crops and food security: evidence from smallholder cocoa and cashew farmers in Ghana
}

\author{
Ishmael Hashmiu* ${ }^{*}$, Olivia Agbenyega and Evans Dawoe
}

\begin{abstract}
Background: Food security is a major development concern worldwide. The use of arable lands to grow cash crops raises additional concerns, yet empirical evidence on the relationship between cash cropping and food security remains inconclusive. Using survey data from 408 randomly sampled households, this paper assesses the income and food security implications of reviving cocoa farming in the Forest-Savannah Transition Zone of Ghana. In addition, the paper examines the influence of socioeconomic factors and diversification into cashew on the food security of cocoa households. Data was collected from 12 rural communities, where food crop production was the main source of livelihood. A causal-comparative design was used. Food security was measured using the USDA Food Security Core Module.

Results: Contrary to the literature that cash crops undermine food security, findings indicate a positive relationship between cocoa farming, household crop income and food security, highlighting complementarities between cocoa, food crop and cashew production. Although income from cocoa alone was not sufficient enough to guarantee food security, it enhanced the financial ability of farmers to diversify into cashew and expand food crop production. This minimised market dependency for food staples, enhanced annual crop income, and ensured a continuous flow of income. Overall, the food security advantage of cocoa farming was predicted by diversification into cashew, displacement of food crops using cocoa, socioeconomic factors, such as land ownership, livestock ownership, and formal education; and marginally by total annual crop income.

Conclusions: Income from cocoa alone is not high enough and widely distributed to guarantee food security. Reinvesting the returns from cocoa in cashew and food crops seems to be a more reliable pathway to enhancing food security than merely depending on the income to buy food. A semi-subsistence system that ensures optimum combination of cash and food crops is, therefore, recommended, but this may require sufficient access to land.
\end{abstract}

Keywords: Cash crops, Food security, Income, Land access, Crop diversification, Forest-Savannah Transition Zone

\section{Introduction}

One of the central questions that has dominated food policy debates is whether cash cropping is an effective strategy for enhancing food security in developing countries

*Correspondence: ihashmiu@gmail.com

Department of Agroforestry, Faculty of Renewable Natural Resources, Kwame Nkrumah University of Science and Technology, PMB, UPO,

Kumasi, Ghana
$[38,73]$. Across the global south, smallholder farmers have been shifting from staple food crop production to cash cropping-a transition that has raised considerable food security concerns $[67,68,73]$. On the other hand, there have been long-term efforts by development agencies and governments, especially in sub-Saharan Africa to promote cash crop production as a strategy to improve food security by increasing incomes [40,79]. original author(s) and the source, provide a link to the Creative Commons licence, and indicate if changes were made. The images or other third party material in this article are included in the article's Creative Commons licence, unless indicated otherwise in a credit line to the material. If material is not included in the article's Creative Commons licence and your intended use is not permitted by statutory regulation or exceeds the permitted use, you will need to obtain permission directly from the copyright holder. To view a copy of this licence, visit http://creativecommons.org/licenses/by/4.0/. The Creative Commons Public Domain Dedication waiver (http://creativeco mmons.org/publicdomain/zero/1.0/) applies to the data made available in this article, unless otherwise stated in a credit line to the data. 
Nevertheless, it remains unclear to what extent and under which conditions can cash crops influence food security [10]. In general, empirical evidence on the relationship between cash cropping and food security remains inconclusive [10, 38, 42, 59]. Some authors posit that cash crops displace food crops [30,44] and undermine food security by rendering households more dependent on market conditions for food [37, 75]. On the contrary, some studies suggest that cash crops rather enhance the food security of farmers by increasing incomes $[41,68,73]$. The question still remains whether income gains from cash crops would be enough to satisfy the food needs of farming households [59].

Despite the centrality of income in the cash crop-food security literature, and the food security concerns generated by the shift from subsistence to commercial agriculture in the developing world, previous studies have not fully examined potential complementarities between cash crops and food crops in understanding farmers' income and food security. There may be potential synergies between cash crops and food crops in determining household food security but these have generally been neglected by research and extension programmes [32]. There is, therefore, the need for future research to determine optimum combinations of cash and food crops required to enhance the food security of cash cropping households [59]. There are additional knowledge gaps on the intersecting role of socioeconomic factors. Although the literature also attributes household food security to socioeconomic factors $[9,13,64,80]$, it is not fully understood how such factors may influence the relationship between cash crop production and household food security [10].

The novelty of this paper lies in examining the role of socioeconomic factors and potential complementarities between cash and food crops in understanding the relationship between cash cropping and household food security. This paper seeks to address the above knowledge gaps in the context of the Forest-Savannah Transition Zone (FSTZ) of Ghana, where subsistence farmers are transitioning towards diverse cash crops. The FSTZ used to support large scale cocoa production but became marginal for cocoa following drought episodes [5] and the 1983 wildfires [77]. This resulted in a shift from cocoa to maize as the dominant crop in the zone [5, 34]. However, following price hikes for cocoa by the Ghana Cocoa Board in the early 2000s [71], many farmers in the zone have been making considerable effort to revive cocoa farming as a strategy to maximise income [12].

Considering that cash crops can displace food crops, the revival of cocoa farming has raised food security concerns [12], yet there is lack of empirical evidence needed to authenticate such concerns in the context of the FSTZ. To fully understand the food security of cocoa households in the FSZ, it is important to examine the intersecting role of crop diversification. This is because the revival of cocoa farming in the FSTZ typically follows a semi-subsistence model: food crop production still remains a significant source of sustenance and income for smallholder households diversifying into cocoa farming [2]. Moreover, climatic changes in the FSTZ have become conducive for cashew [43], causing many cocoa farmers to also diversify towards cashew production [2, 63]. Despite ample evidence that crop diversification is potentially effective for managing income and food security risks $[6,15,45]$, research is lacking in the context of cocoa farming in the FSTZ. Previous studies have disproportionately focused on potential displacement of cocoa by cashew [2,63] and food crops [72], while knowledge of potential complementarities between cocoa, cashew and food crops in determining the income and food security of smallholder households in the zone remains deficient. In addition, some studies (e.g., $[11,16,67])$ have emphasised the importance of land availability for staple food crop production in enhancing the food security of cash crop households, but quantitative evidence is lacking in this regard.

Accordingly, this paper seeks to understand the food security implications of reviving cocoa farming in the FSTZ while highlighting the intersecting role of socioeconomic factors and crop diversification. Specifically, the paper attempts to address the following questions: (1) how does the revival of cocoa farming affect the annual crop income and food security of smallholder households in the FSTZ of Ghana? (2) What is the effect of income on the food security of cocoa households? (3) Are there any complementarities between cocoa, cashew and food crop production in enhancing the income and food security of smallholder households, and what is the intersecting role of land access? (4) How do socioeconomic factors and a diversified stock of cashew and food crops influence the food security of cocoa households? This paper focuses on cocoa and cashew, since they are the major industrial crops cultivated in the study area. The paper extents the cash crop-food security literature by highlighting the intersecting role of socioeconomic factors and crop diversification. The paper also highlights potential entry points for enhancing the food security of subsistence households that are transitioning towards commercial agriculture.

\section{Cash crops and food security}

Ensuring food security, especially in developing countries is an issue that has received considerable attention in academic and international policy debates [38]. Despite its global importance, the concept of food security remains elusive due to vague and excessively broad definitions $[56,62]$. The term "food security" has been broadly 
defined as "access by all people at all times to sufficient food for an active and healthy life" [76]. Another broad but widely accepted definition was subsequently coined by the World Food Summit: "food security exists when all people, at all times, have physical and economic access to sufficient, safe and nutritious food that meets their dietary needs and food preferences for an active and healthy life" [25]. FAO's definition looks at food security from four dimensions: availability, accessibility (physically and economically), utilisation (quality, safety and nutritional value) and stability of these three dimensions. Despite the wide acceptance of FAO's definition, Pinstrup-Anderson [56] argues that per that definition, a household that is able to acquire the preferred and nutritious foods for all its members could be classified as food insecure if one of the members suffer from micronutrient deficiency due to inappropriate intra-household food allocation. The author, therefore, suggests the need to disaggregate the food security concept into different categories of food insecurity based on the nature and severity of the problem and the kind of solution required.

Achieving a comprehensive and standardised measure of food security has also been problematic. Although a number of indicators (e.g., Global Hunger Index, Global Food Security Index, Food Production Index etc.) have been proposed over the years to measure and monitor food security dimensions at the macro level, measuring the food security phenomenon as a whole still remains a challenge according to Santeramo [62]. The author, therefore, proposes the development of composite indices using subindices that convey distinct set of information. At the individual and household levels, Haddad et al. [33] also posit that relatively simple indicators such as dietary diversity or other quantitative measures of food consumption perform well in identifying the food and nutrition insecure than macro-level indicators, such as the Food Production Index. A classic example of such quantitative measures is the United States Department of Agriculture (USDA) Food Security Core Module [17], which was employed in this study to measure food security ("Methods of data collection" section). The USDA module uses a set of 10-18 simple questions that relate to the various dimensions of food security to compute composite scores for household food security in the last 12 months. From the perspective of Pinstrup-Andersen [56], the USDA food security measure is also advantageous for differentiating between different categories of food insecurity.

Beyond the generic issues on food security definition and measurement, conceptualisation of food security has been particularly problematic in cash crop production contexts. Despite long-term efforts by development agencies and governments to promote cash crop production as a strategy to improve food security, the literature still remains inconclusive on the relationship between cash cropping and food security [10, 38, 73]. According to Jarzebski et al. [38], the lack of a clear understanding of the food security impacts of cash crops is due to the large diversity of cash crops, and differences in their modes of production, production areas, and impact mechanisms. On the negative side, several studies have shown that cash crops undermine food security by displacing food crops. Empirical evidence from Kenya [44] indicates that sugarcane production undermined the food security of smallholder farmers by limiting land allocation to subsistence vegetable production. Similarly, a growing number of studies (e.g., $[18,21,30])$ are pointing to increased food insecurity risks of land conversion for biofuels. The authors argue that biofuel crops displace food crops, and this could compromise the food security of rural and urban communities by resulting in increased food scarcity and higher food prices. Several other authors (e.g., [37, 75]) concur that cash cropping undermine food security by rendering households more vulnerable to market conditions for staple foods. During the 2001-2003 food price shocks in Malawi for instance, Wood et al. [75] observed that children of cash crop farmers who were in utero experienced disproportionately lower nutritional health outcomes compared to their food crop farming counterparts. Immink and Alarcon [37] elaborate that as cash crops displace food crop production, household consumption of staple foods from own production is reduced, thereby increasing market dependency for food. According to Anderman et al. [10], cash cropping households are more vulnerable to food insecurity because income from cash crops is usually not enough to match increasing global and local food prices. The authors found that income from cocoa in Ghana was not enough to meet household expenditure on food, especially as profits were seasonal. The authors maintain that cocoa farming limits food access by shifting income distribution from continuous flows to lump sums.

On the other hand, a growing body of literature contends that cash crops enhance food security by increasing incomes. Findings from Zimbabwe [59] suggest that income gains from cash crops impacted positively on household dietary diversity score. Evidence from Ethiopia [41] similarly indicates that income gains from coffee improved food security, even after controlling for total income. The authors expatiate that unlike food crops, coffee sales occur almost throughout the year, thereby providing a continuous flow of income that enables farmers to smooth consumption during the lean season. Several other authors (e.g., $[4,73])$ further posit that growing cash crops is likely to enhance food security, not only by increasing incomes, but also by complementing food crop production. Some studies (e.g., [32, 68]) similarly indicate positive spillover effects of cotton production 
on food crop production by enhancing farmers' access to agricultural inputs. This is consistent with findings from Zambia [31], where jatropha farmers maintained staple food production by expanding their cropping areas. A similar result was obtained in Malawi, where farmers used income from tobacco to pay for additional labour for maize production [53].

Following the theory of entitlements [64], this paper conceptualises the food security implications of cash crop production as a function of socioeconomic assets of households. The theory of entitlements considers famine (a state of food insecurity) as more of a socioeconomic rather than a food availability problem. It postulates that food availability alone cannot guarantee access to food by all,access to food by individuals and groups depends largely on their entitlements, which are classified into four: production-based (growing food), trade-based (buying food), own-labour (working for food), and inheritance/social transfers (gift). Thus, in a given context, access to food by individuals or households is dependent on self-production, income, purchasing power, labour potency, and social support [64]. Accordingly, this study theorised that the revival of cocoa farming by subsistence farmers in the FSTZ could displace food crops but may not necessarily undermine food security, since the determining factors go beyond self-production.

Based on the literature that cash cropping leads to higher income, we hypothesise that cocoa-farming households (CFHs) in the FSTZ have higher average annual crop income (trade-based entitlement) than noncocoa farming households (NCFHs). Such income advantage is expected to give CFHs higher purchasing power, better market access to food and ultimately higher food security than NCFHs. Similarly, food security is expected to increase with cocoa income. Thus, households with higher income from cocoa are likely to attain higher food security. Higher food security is also anticipated in cocoa households that had diversified into cashew, since such households combine the income advantage of two major cash crops. Thus, cashew is anticipated to complement the expected positive effect of cocoa farming on food security. Differences in crop income (trade-based entitlement) is expected to be the primary determinant of household food security, considering that CFHs in the FSTZ typically cultivate food crops and possess production-based entitlements, such as NCFHs. Nevertheless, food security is expected to be lower or less likely in households that used cocoa to directly displace food crops (i.e., undermine their production-based entitlements) compared to those that might have established cocoa on non-food crop lands. Maintenance of food crop production is expected to augment the income and production-based entitlements of CFHs, and hence, likely to help explain food security.

Following the empirical literature, the food security of CFHs is also expected to be influenced by socioeconomic factors besides income. Food security is hypothesised to be negatively influenced by household size $[9,61]$. However, it is expected to be positively influenced by the age $[8,80]$, level of education $[13,45,47,50,80]$ and farming experience of the household head $[8,52]$, as well as with household agricultural labour size [46]. The sex of the household head (being a female) [10, 29], land ownership $[9,28,50,58]$, livestock ownership [35, 47, 50, 74], access to extension $[3,19]$, credit $[13,14,45]$ and offfarm income $[23,54]$ are also expected to positively influence the food security of CFHs.

\section{Study area and methodology \\ Description of the study area}

The study took place in the Offinso North District $\left(7.39^{\circ} \mathrm{N}, 1.95^{\circ} \mathrm{W}\right)$, Mampong Municipal $\left(7.05^{\circ} \mathrm{N}, 1.40^{\circ}\right.$ W), Techiman North District $\left(7.63^{\circ} \mathrm{N}, 1.91^{\circ} \mathrm{W}\right)$ and Wenchi Municipal $\left(7.74^{\circ} \mathrm{N}, 2.10^{\circ} \mathrm{W}\right)$ in Ghana. Offinso North and Mampong are in the Ashanti Region, whereas Wenchi and Techiman North are in the Bono East Region (Fig. 1). The study was conducted in 12 communities, where cocoa farming was actively being revived by subsistence farmers. Three communities were selected from each district/municipality. These were Seseko, Sraneso No. 2 and Tanokwaem in the Offinso North District; Atonsuagya, Adidwan and Abuontem in the Mampong Municipal; Asueyi, Aworowa and Krobo in the Techiman North District; and Tromeso, Ayigbe and Mallamkrom in the Wenchi Municipal.

The study area is largely an area of derived savannah between the High Forest Zone (HFZ) to the south and the Guinea Savannah Zone to the north, hence the name Forest-Savannah Transition Zone. It is an expanding zone along the forest fringes, where grassland is continually replacing forest [24]. The climate and soil are suitable for crops grown in both the forest and savannah zones. Crop farming is, therefore, the predominant source of livelihood in the area.

\section{Sampling technique}

A multi-stage sampling technique was used to select regions, districts, communities and households for data collection. The first stage involved purposively selecting two administrative regions (Ashanti and Bono East). These regions were selected because of considerable efforts being made by farmers to revive cocoa production in the forest-savannah transitional areas of both regions. At the second stage, a list of administrative districts in the FSTZ of both regions, where cocoa 


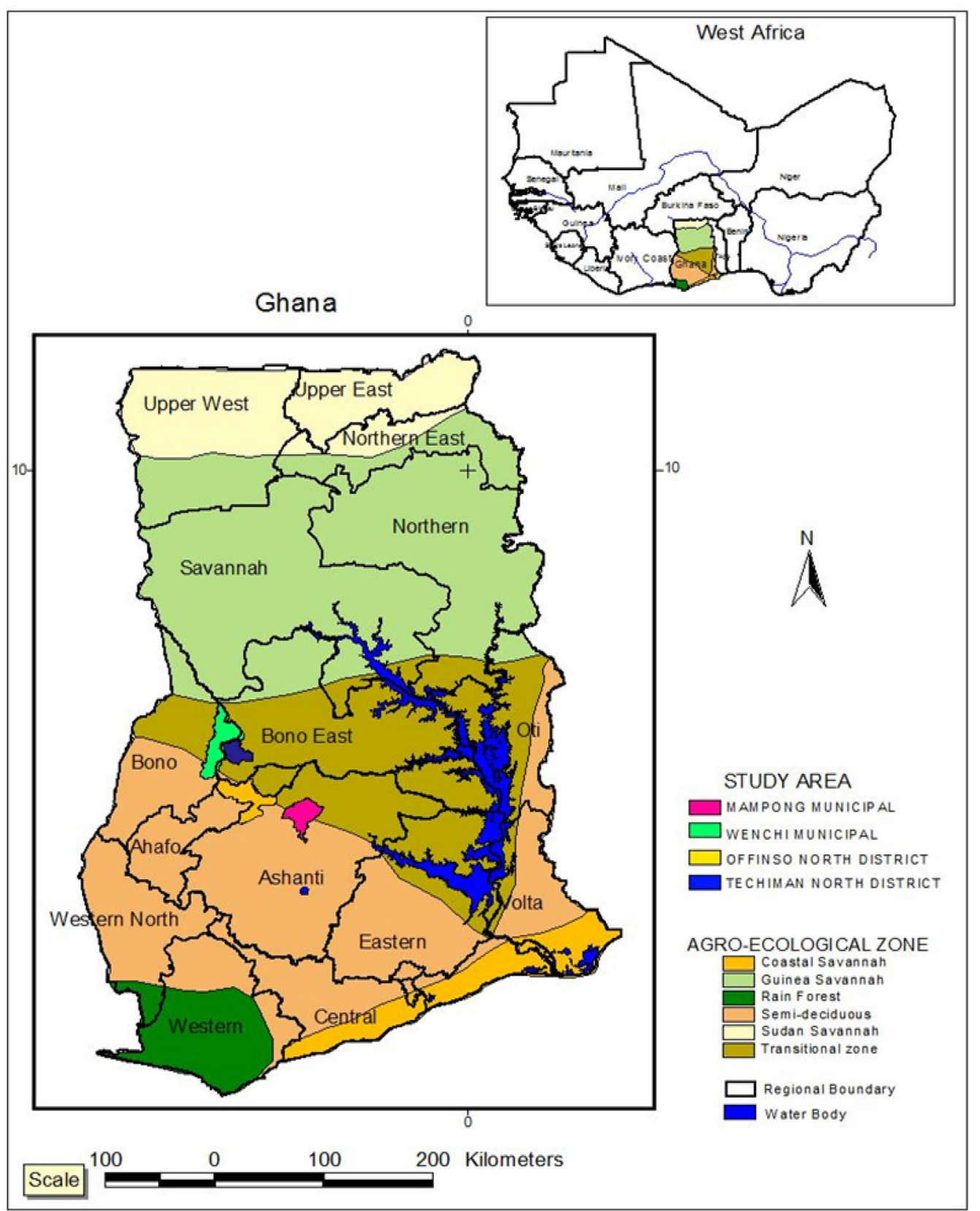

Fig. 1 Regional and agroecological map of Ghana showing the study districts and municipalities ( adapted from [57])

farming was being revived was obtained from the Cocoa Health and Extension Division (CHED). Two districts were randomly selected from each region. The Offinso North District and Mampong Municipal were selected from the Ashanti Region; and the Techiman North District and Wenchi Municipal from the Bono East Region (Fig. 1). At the third stage, a list of communities in the selected districts, where cocoa farming was actively being revived was obtained from CHED, following which three communities were randomly selected from each district, making a total of 12 communities.

The final stage was a random selection of households in each of the 12 communities. A list of compounds in each of the communities was obtained from a team of community leaders (chiefs, assemblymen, unit committee members, chief farmers and executives of local farmers' association). Thirty-four compounds were randomly selected per community. In selected compounds 
which had only one farming household, that household was automatically selected. However, in the case of compounds which had multiple farming households, only one household was randomly selected. A total of 408 households were, therefore, selected. This sample size was above a minimum of 384 derived from Cochran's [20] sample size formula for a large population. The household was chosen as the unit of analyses because risk management strategies start with decisions at the farm and household levels [51]. A household in this study is defined as 'a group of people who own the same productive resources, live together and feed from the same pot' ([78]:129). That occasionally consisted of just one person.

\section{Methods of data collection}

The main tool for data collection was a structured questionnaire (Appendix 1) administered to 408 household heads. Household heads were targeted because they were generally the primary decision makers at the household level in the study area. The questionnaire was used to collect data on the demographic characteristics of household heads, households' crop choice decisions on cocoa and cashew, livelihood assets, income from cocoa, gross annual crop income, and food security status. Openended questions were incorporated to allow respondents to provide additional information. Gross annual crop income (GACI) was estimated by obtaining the quantities of cocoa, cashew and food crops sold in the last 12 months (2016/17), and using the average price per unit to estimate income from each crop. As justified in "Cash crops and food security" section, household food security was measured using the USDA Food Security Core Module. The USDA module measures food security on a scale of 0.0 to 9.3, on which higher scores represent lower food security (i.e., higher food insecurity). A score of 0.0-2.2 categorically means 'food secure', while scores above 2.2 represent various categories of food insecurity (Table 1).

The food sources and self-reported trends in food production in the last 10 years (2007-2017) were also investigated, and compared between cocoa and non-cocoa households. Ten years was used because the revival of cocoa farming in the study communities (as reported by the executives of local cocoa farmers' associations during reconnaissance visits) generally began around 2006/2007. Data collection lasted for 6 months; from March 2017 to September 2017.

\section{Data analyses}

Data was analysed using IBM SPSS software (v.20). Differences in mean food security score and annual crop income between cocoa and non-cocoa households were assessed using Mann-Whitney $U$ test $(p<0.05)$. Multiple
Table 1 Numeric and categorical measures of food security based on the USDA food security core module

\begin{tabular}{ll}
\hline Range of food security & Categorical food security status \\
\hline $0.0-2.2$ & Food Secure \\
$2.4-4.4$ & Food Insecure Without Hunger \\
$4.7-6.4$ & Food Insecure Without Hunger, Moderate \\
$6.6-9.3$ & Food Insecure Without Hunger, Severe \\
\hline
\end{tabular}

regression was used to estimate the determinants of food security in CFHs, taking the necessary data requirements into account. The model was specified as follows:

$$
\begin{aligned}
\text { SECURITY }= & \beta_{0}+\beta_{1}(S E X)+\beta_{2}(A G E)+\beta_{3}(E D U) \\
& +\beta_{4}(F E X)+\beta_{5}(C O E X)+\beta_{6}(S I Z E) \\
& +\beta_{7}(L A B)+\mathrm{B}_{8}(L A N D)+\beta_{9}(L I V E) \\
& +\beta_{10}(\text { GACI })+\beta_{11}(C I N C)+\beta_{12}(\text { OFF }) \\
& +\beta_{13}(E X T)+\beta_{14}(C R E D)+\beta_{15}(C A S H E W) \\
& +\beta_{16}(D I S P)+\epsilon
\end{aligned}
$$

where $\beta_{0}$ is the intercept (also known as the constant), $\beta_{1}$ to $\beta_{16}$ are the slope parameters (also referred to as the slope coefficients) for the respective independent variables, and $\varepsilon$ represents the sample residuals or errors. SECURITY was the outcome variable representing the food security of cocoa households as estimated using the USDA Food Security Core Module. It was a continuous variable which ranged from 0.0 to 9.3 in decreasing order of food insecurity. Thus, a negative change in the outcome variable would indicate an increase in food security. The explanatory variables were socioeconomic factors drawn from the literature ("Cash crops and food security" section). SEX was a dichotomous variable that took a value of 1 if the household head was a male; 0 if female. $A G E$ was a continuous variable representing the age of the household head in years. $E D U$ was a binary variable which denotes formal education of the household head: 1 if completed at least primary education; 0 if otherwise. A minimum of primary qualification was used as a benchmark because according to the International Standards Classification of Education [69], primary education establishes a solid foundation for learning and understanding core areas of knowledge.

FEX represents farming experience of the household head, i.e., number of years the household head has been farming in general. COEX denotes number of years the household head has been farming cocoa. SIZE was household size measured as a continuous variable. $L A B$ was also a continuous variable representing number of household members that provided farm labour. LAND 
was a continuous variable on the number of separate farmlands owned by a household. LIVE represents livestock ownership measured as a binary variable. It took a value of 1 if any household member owned livestock, and 0 if none. CINC represents gross annual income from cocoa, while $G A C I$ donates gross household income from cocoa, cashew and food crops in the last 12 months $(2016 / 17)$ measured in thousands of Ghana Cedis. OFF took a value of 1 if a household had off-farm income; 0 if otherwise. EXT was a binary variable representing access to extension in the last 12 months (2016/17). It was coded 1 if any and 0 if none. CASHEW took a value of 1 if a CFH had diversified into cashew; 0 if otherwise. $D I S P$ was a dichotomous variable denoting displacement of food crops by cocoa in the last 20 years (1997-2017). A timeframe of 20 years was used because according to executives of local cocoa farmers' association, there were few attempts to revive cocoa farming in the late $90 \mathrm{~s}$ before the revival gained momentum around 2006/2007. DISP assumed a value of 1 if a household established cocoa on land that was being used to grow food crops; 0 if otherwise. CRED was coded 1 if any household member had accessed cash or input credit in the last 3 years (2014-2017); and 0 if otherwise. Three years was used as the timeframe because it takes about 3 years for the hybrid cocoa variety commonly grown in the study area to mature, and for that matter, for any credit accessed to affect returns from cocoa.

The multiple regression model estimated how each of the independent variables influenced the food security scores of CFHs. In addition, multinomial logistic regression was used to assess the influence of the above independent variables on the different categories of food security (Table 1) in CFHs. The food secure category was used as the reference category.

\section{Results}

Effects of cocoa farming on household food security and crop income

Food insecurity was highly prevalent regardless of the cocoa farming status of households. Approximately 64\% of the 408 households were food insecure and fell into different categories of food insecurity: food insecure without hunger $(17.40 \%)$, food insecure with hunger (moderate) $(27.70 \%)$ and food insecure with hunger (severe) (18.90\%). Findings suggest that cocoa farming had a positive effect on household food security. Food insecurity was less prevalent in CFHs (57.50\%) compared to NCFHs (73.21\%) (Fig. 2). Thus, a higher proportion of CFHs (42.50\%) were food secure compared to NCFHs (26.79\%). Overall, only $36.03 \%$ of households were food secure, of which the vast majority (69.39\%) were CFHs.

In addition, CFHs recorded lower food insecurity scores (FISs) than NCFHs on the USDA scale. The mean FIS of CFHs was $3.18( \pm 0.18)$ compared to $4.12( \pm 0.21)$ for NCFHs. The FISs were not normally distributed, as indicated by Shapiro-Wilk's test $(p>0.05)$ and normal Q-Q plots. Mann-Whitney $U$ test (a non-parametric test) was, therefore, used to assess the difference in scores observed. The distributions of the scores for both groups

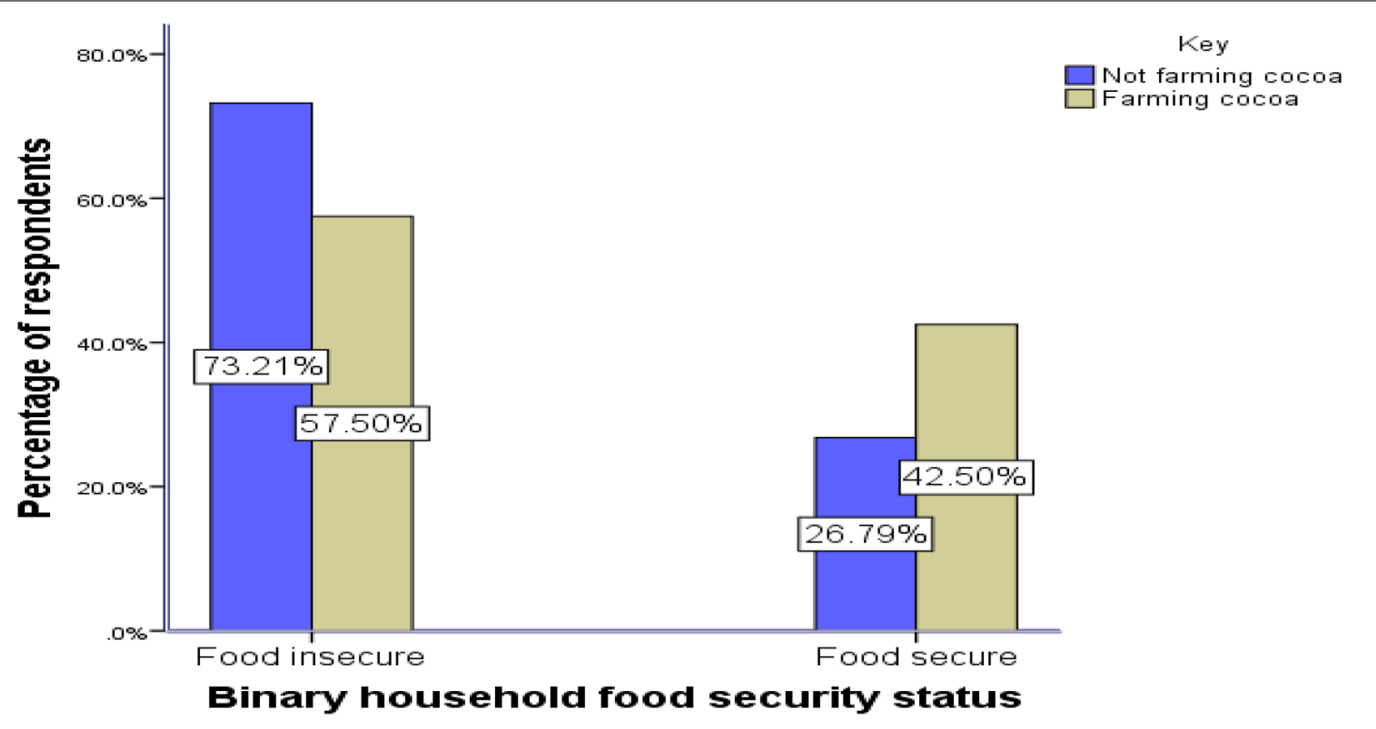

Error bars: $95 \% \mathrm{Cl}$

Fig. 2 Food security status of cocoa vs. non-cocoa farming households in the Forest-Savannah Transition Zone of Ghana ( $n=408$ ) 
were similarly shaped as determined by a visual inspection. The median was, hence, used as a measure of central tendency. CFHs had significantly lower median FIS (3.40) than NCFHs (5.10), $U=16,233, z=-3.394, p=0.001$.

Similarly, a positive relationship was observed between cocoa farming and the gross annual crop income (GACI) of farming households. The mean GACI of all the households was GHS $6758.56 \pm 480.73$. Nineteen households $(4.66 \%)$ were excluded from the analyses because they were unable to estimate their GACI. The average GACI reported by CFHs was GHS 8586.91 \pm 712.08 , which was about 2.2 times greater than that of NCFHs (GHS $3907.76 \pm 442.40)$. The income data was not normally distributed, as determined by Shapiro-Wilk's test $(p>0.05)$ and normal Q-Q plots. The income difference observed was assessed using Mann-Whitney $U$ test. The distributions of the income data were similar as determined by a visual inspection. Median GACI for CFHs (GHS 5113) was significantly higher than NCFHs (GHS 2100), $U=10,417, z=-7.020, p=0.000000$. Cocoa income was controlled for to rule out the influence of other cash crops on the higher GACI of CFHs. Median GACI of CFHs with no income from cocoa was GHS 2822, which was not significantly different from that of NCFHs (GHS 2100), $U=2918, z=-1.072, p=0.284$ (Fig. 3). Thus, the higher GACI of CFHs was to some extent, influenced by income from cocoa.
Effect of income on the food security of cocoa households Two categories of income are analysed in this section: gross income from cocoa alone and aggregated income from cocoa, cashew and food crops. Income from cocoa alone accounted for $38.06 \%$ of GACI and was noted by some CFHs to have enhanced their ability to purchase high-quality food products from the market. Some CFHs also expressed increased ability to save money to sustain consumption during the lean season, which was indicated to last from March to July. Although the majority of farming households (69.85\%) reported food shortage during the lean season, a lower the proportion of CFHs (69.08\%) did so compared to NCFHs (80.95\%). Despite the positive observations made by farmers, results from the multiple regression model ("Determinants of food security in cocoa farming households: assessing the influence of socioeconomic factors and crop diversification" section) showed that income from cocoa alone was not high enough to positively influence food security $(P=0.842)$. However, the model showed that GACI, i.e., income from cocoa, cashew and food crops positively influenced the food security of CFHs $(P=0.0042)$. A line graph was used to examine the relationship between the GACI and food security status of CFHs (Fig. 4). The graph corroborates that the transition from food insecurity to food security in cocoa households was positively related to GACI. The graph further depicts that for

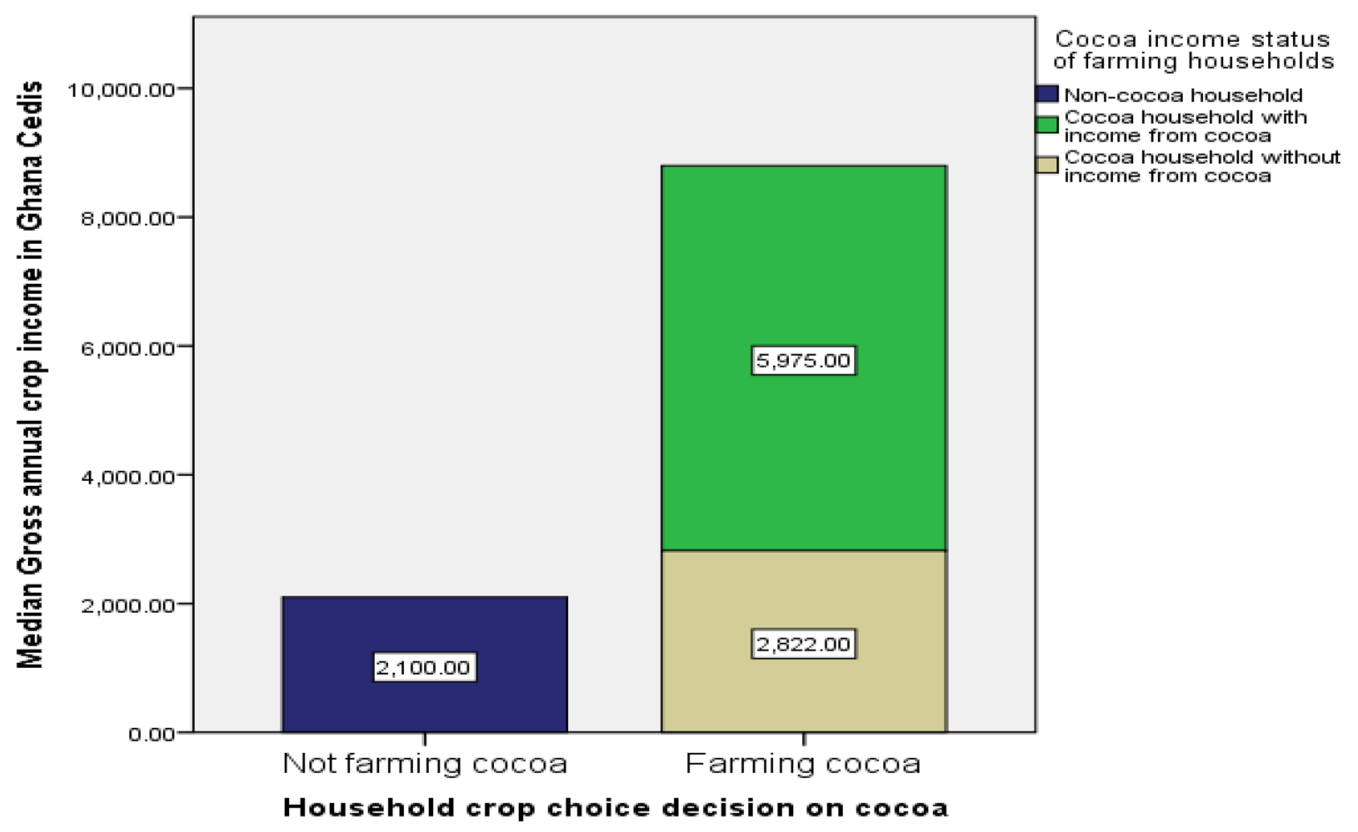

Fig. 3 Median crop income based on cocoa income status of farming households in the Forest-Savannah Transition Zone of Ghana ( $n=408$ ) 


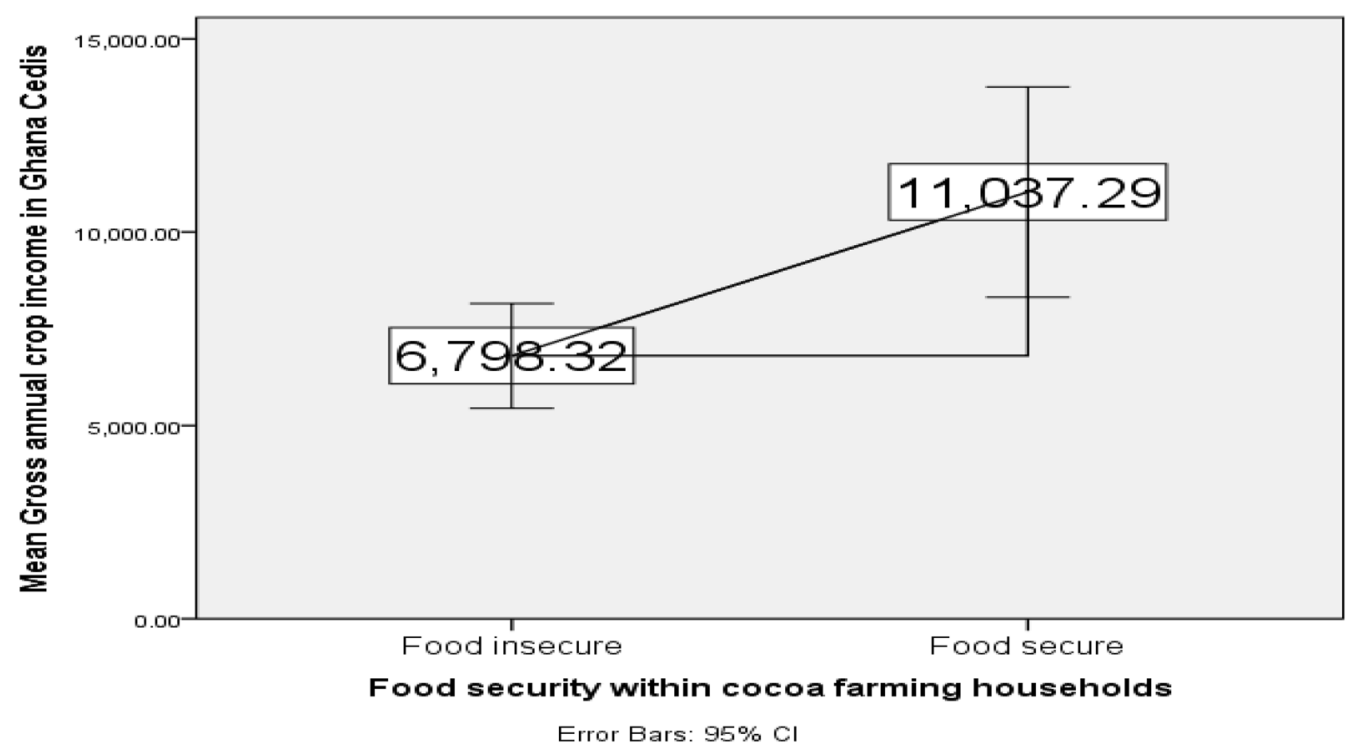

Fig. 4 Relationship between the food security and annual crop income of cocoa households in the Forest-Savannah Transition Zone of Ghana $(n=240)$

food insecure CFHs to transition to food security, their mean GACI had to increase from GHS 6798.32 to GHS $11,037.29$, i.e., increase by a margin of $62.35 \%$.

\section{Complementarities between cash crops and food crop production}

(i) Between cocoa and food crops

All the CFHs were into food crop production. Findings indicate complementary effect of income from food crop production in enhancing the GACI of CFHs over that of NCFHs. The average household income from cocoa alone was GHC $3605.93 \pm 348.10$, which was less than the GACI of NCFHs (GHS 3907.76 \pm 442.40 ). However, the GACI of CFHs increased to GHC $5840.72 \pm 522.51$, i.e., exceeded that of NCFHs when income from food crops was considered. On the other hand, income from cocoa was also linked to expansion in food crop production. Beyond the standard practice of intercropping cocoa and food crops in the first 3 years, some households indicated to have used income from cocoa to buy separate lands for food crops and to expand existing food crop farms. One farmer narrated: "I own four farms; one cocoa farm and three food crop farms, and I normally use the money I get from cocoa to expand and maintain the food crop farms". Some CFHs also reported to have used the returns from cocoa to develop their fallow lands into food crop farms. Consequently, a comparative analysis of the dominant sources of staple foods of the various households (Fig. 5) indicated that the vast majority of CFHs (85.42\%) depended mainly on self-produced food; a percentage which exceeded that of NCFHs (73.81\%). On the other hand, a greater proportion of NCFHs (18.45\%) cited the market as their main source of staple foods compared to CFHs (8.75\%).

Following the argument that cash crops undermine food security by displacing food crops ("Introduction" section), self-reported trends in household food production in the last 10 years (2007-2017) were also examined and compared between CFHs and NCFHs (Fig. 6). Although most of the households (69.12\%) indicated a downward trend in food production, a lower proportion of CFHs (65\%) did so compared to NCFHs (75\%). A greater percentage of CFHs $(27.50 \%)$ also reported increasing food production compared to NCFHs (14.88\%).

In addition, major reasons underlying the downward trend in food production were examined and the perceived contribution of cocoa farming was ascertained. Fourteen reasons were cited by farmers for declining food production (Fig. 7). The main reason indicated was drought (60.99\%), followed by lack of money $(14.18 \%)$ and declining soil fertility (8.87\%). Only $3.60 \%, 1.10 \%$, and $2.50 \%$ cited cocoa, cashew, and both cocoa and cashew, respectively, as the causes of declining food production.

(ii) Between Cocoa and Cashew

Some CFHs reported to have invested income from cocoa in cashew production. The majority of CFHs (59.17\%) had, therefore, diversified into cashew farming, compared to only $29.76 \%$ of NCFHs. Findings also indicate complementarities between cocoa and cashew 


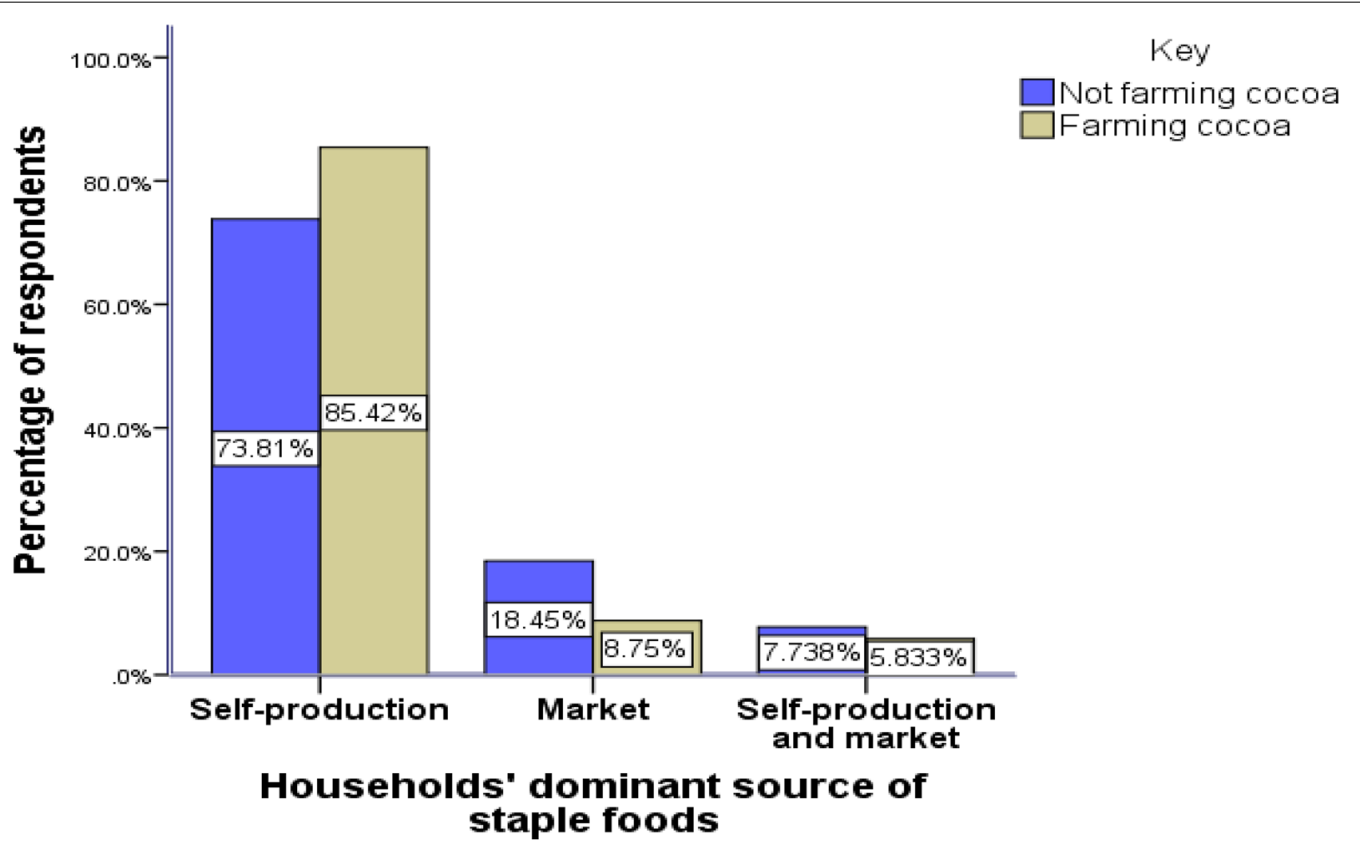

Error bars: $95 \% \mathrm{Cl}$

Fig. 5 Dominant sources of staple foods of farming households in the Forest-Savannah Transition Zone of Ghana $(n=408)$

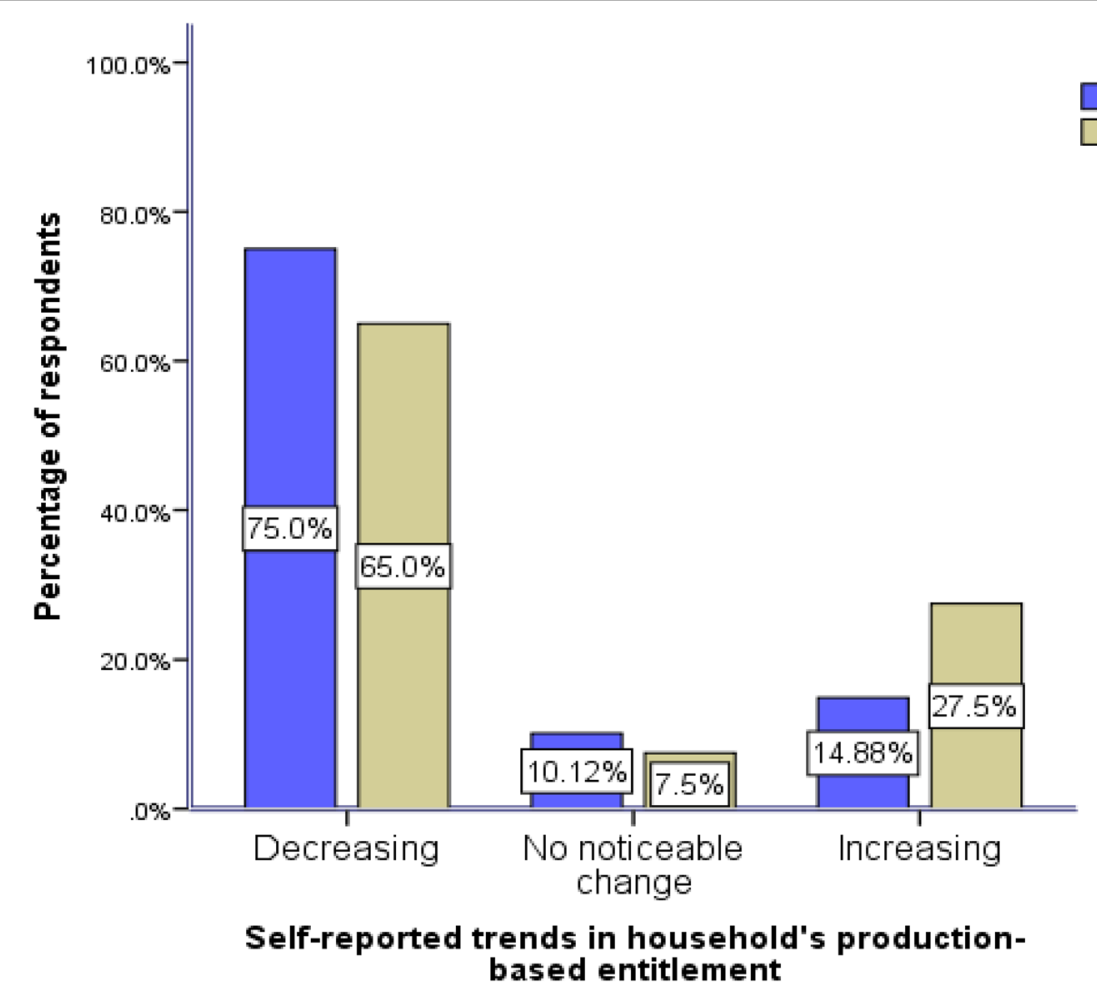

Key

Not farming cocoa

Farming cocoa

Error bars: $95 \% \mathrm{Cl}$

Fig. 6 Trends in food production in the last 10 years (2007-2017) as reported by farming households in the Forest-Savannah Transition Zone of Ghana $(n=408)$ 


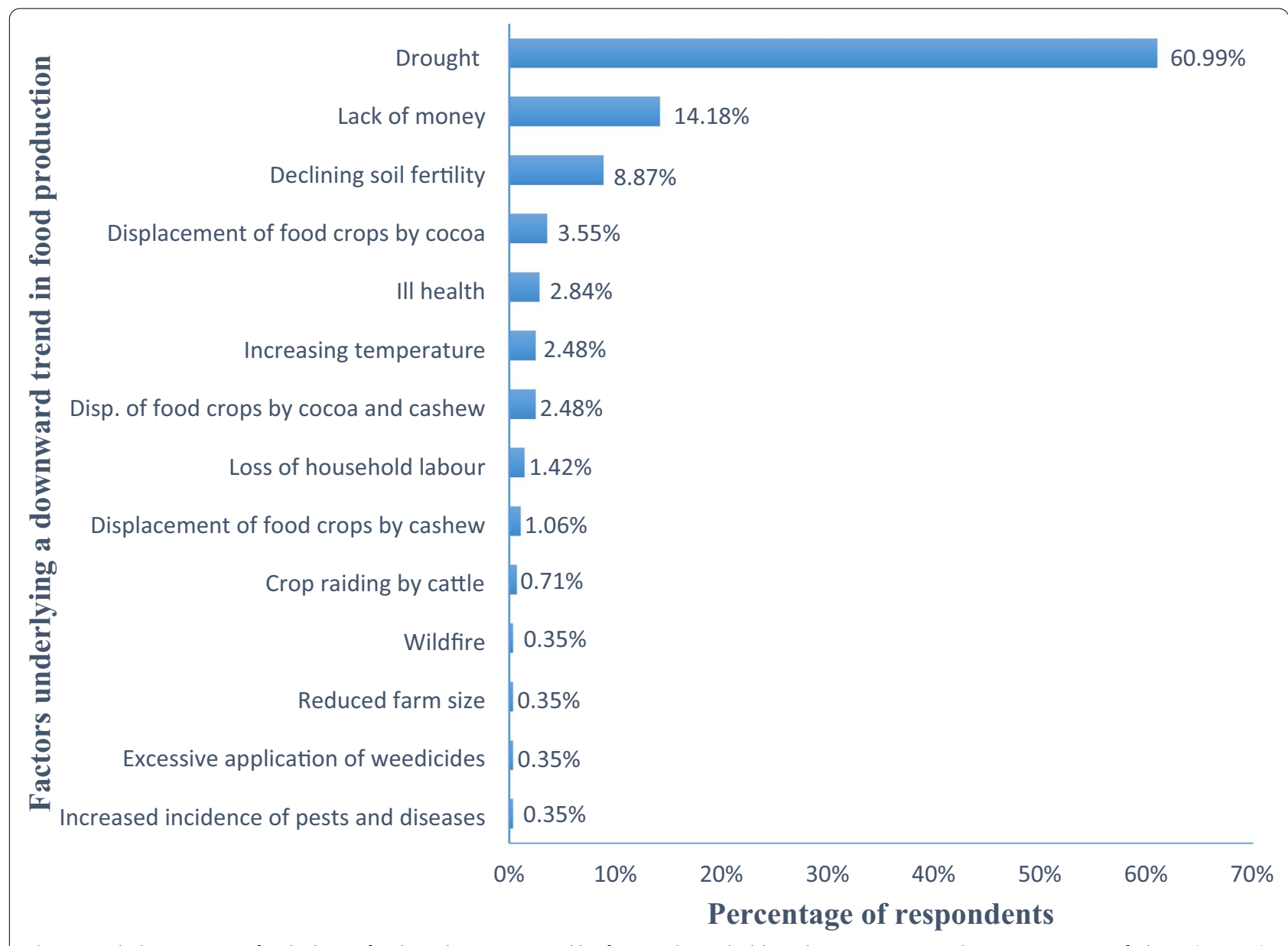

Fig. 7 Underlying reasons for declining food production as cited by farming households in the Forest-Savannah Transition Zone of Ghana ( $n=282)$

in enhancing the GACI and trade-based entitlements of CFHs. CFHs that had diversified into cashew reported higher mean GACI (GHS 8372.91 \pm 943.70 ) compared to those not farming cashew (GHS 5840.72 \pm 522.51 ). Median GACI of CFHs cultivating cashew (GHS 5775.00) was also significantly higher than that of those not farming cashew (GHS 3000), $U=22,504, z=-4.710$, $p=0.000$. Returns from cashew, according to farmers, also ensured a continuous flow of income, which helped to sustain consumption during the lean season. Farmers observed that the harvest time for cashew (January-May) began at the end of the peak season for cocoa (OctoberJanuary) and coincided with the lean season for staple foods (March-July).

(iii) The intersecting role of land access

Land access was noted to play a major role in cocoa farmers' ability to diversify into cashew and expand food crop production. Generally, CFHs reported better access to land than their non-cocoa counterparts. The majority of CFHs (approximately 75\%) owned farmland compared to only $27.38 \%$ of NCFHs. Nearly half of CFHs (49.17\%) also owned fallow lands compared to $13.10 \%$ of NCFHs. A number of CFHs (37.90\%), therefore, indicated to have established cocoa on fallow lands rather than by displacing food crops. Fallow land was customarily considered as land surplus and an indicator of sufficient land access in the study area. Most CFHs (67.91\%) also owned multiple (separate) farmlands, which ranged from two to eleven. CFHs owned an average of 2.61 separate farmlands, which greatly exceeded that of NCFHs $(0.60)$. The multiple regression model ("Determinants of food security in cocoa farming households: assessing the influence of socioeconomic factors and crop diversification" section) corroborates that the number of separate parcels of farmland owned increased the of food security of CFHs $(P=0.073)$. For every unit increase in the number of separate farmlands owned by a cocoa household, food security increased by -0.162 ("Determinants of food security in cocoa farming households: assessing the influence of 
socioeconomic factors and crop diversification" section). Some NCFHs, however, criticised that in an attempt to cash in on cocoa, some landowners had started taking away lands from tenant food crop farmers to grow more cocoa. Approximately $22 \%$ of cocoa household heads confirmed that their cocoa farmlands used to be rented by tenant food crop farmers who were displaced following the decision to grow cocoa. Nevertheless, farmers did not generally associate cocoa farming with declining food production.

\section{Determinants of food security in cocoa farming households: assessing the influence of socioeconomic factors and crop diversification}

The preceding sections have highlighted positive relationships between cocoa farming and various aspects of

Table 2 Descriptive statistics of the determinants of food security in cocoa households in the Forest-Savannah Transition Zone of Ghana $(n=236)$

\begin{tabular}{|c|c|c|}
\hline Categorical variables Number of respondents & $(n)$ & $\%$ \\
\hline \multicolumn{3}{|l|}{ Sex of the Household Head } \\
\hline Male & 208 & 88.14 \\
\hline Female & 28 & 11.86 \\
\hline \multicolumn{3}{|l|}{ Education Level of the Household Head } \\
\hline Completed at least primary education & 171 & 72.46 \\
\hline Did not complete primary education & 65 & 27.54 \\
\hline \multicolumn{3}{|l|}{ Livestock ownership } \\
\hline Yes & 170 & 72.03 \\
\hline No & 66 & 27.97 \\
\hline \multicolumn{3}{|l|}{ Access to off-farm income } \\
\hline Yes & 127 & 53.81 \\
\hline No & 109 & 46.19 \\
\hline \multicolumn{3}{|l|}{ Access to extension in the last 12 months } \\
\hline Yes & 176 & 74.56 \\
\hline No & 60 & 25.44 \\
\hline \multicolumn{3}{|l|}{ Access to cash or input credit in the last 3 years } \\
\hline Yes & 43 & 18.22 \\
\hline No & 193 & 81.78 \\
\hline \multicolumn{3}{|l|}{ Farming cashew } \\
\hline Yes & 140 & 59.32 \\
\hline No & 96 & 40.68 \\
\hline \multicolumn{3}{|l|}{ Displacement of food crops using cocoa } \\
\hline Yes & 147 & 62.29 \\
\hline No & 89 & 37.71 \\
\hline Continuous variables & & Mean \pm SD \\
\hline Age of the household head (years) & & $53.85 \pm 12.85$ \\
\hline Farming experience of the household head (years) & & $24.97 \pm 13.18$ \\
\hline Cocoa farming experience of the household head (years) & & $9.79 \pm 7.28$ \\
\hline Household size & & $7.01 \pm 3.46$ \\
\hline Number of separate farmlands owned & & $2.62 \pm 2.20$ \\
\hline Household labour size & & $3.21 \pm 1.96$ \\
\hline Household gross annual crop income in thousands of Ghana Cedis & & $8.60 \pm 10.98$ \\
\hline Household gross annual income from cocoa in thousands of Ghana Cedis & & $3.03 \pm 4.68$ \\
\hline
\end{tabular}

The model automatically excluded four households from the analyses because they were unable to estimate their total crop or cocoa income.

${ }^{\text {a }}$ The estimate incorporated households with no income from cocoa. The figure is therefore lower than the average figure obtained from households who were earning from cocoa 
food security. The present section uses multiple regression to estimate the influence of socioeconomic factors and crop diversification on the food security scores of CFHs. Descriptive statistics of independent variables included in the model are presented in Table 2.

The assumption of linearity was met as assessed by partial regression plots and a plot of studentised residuals against the unstandardized predicted values. A visual inspection of the plot of studentised residuals against the unstandardized predicted values further showed that there was homoscedasticity. Durbin-Watson statistic of 1.831 was obtained, suggesting independence of observations. There was no multicollinearity. The highest variance inflation factor was 2.07 . All the studentised deleted residuals were below \pm 2.5 , indicating that there were no outliers. No highly influential points were detected as the highest value for Cook's distance was 0.232 . The requirement of normality was met, as assessed by a Normal P-P Plot of the Standardized residuals.
The multiple regression results, as well as the goodness of fit and model performance statistics are summarised in Table 3.

The fitted model significantly predicted the food security of CFHs, $F(16,95)=3.364, p<0.0005$, adjusted $R^{2}=0.139$. Four out of the 16 predictor variables were statistically significant. These were cashew farming $(p=0.000)$, education level of the household head $(p=0.023)$, gross annual income from cocoa, cashew and food crops $(p=0.042)$ and number of separate farmlands owned $(p=0.073)$. The most influential factor was diversification into cashew (standardised coefficient $=-0.283$ ). Households farming cashew alongside cocoa had food security -1.569 greater than those farming only cocoa. Food security was also -0.965 greater in cocoa households headed by people with primary school qualification and above, compared to those headed by people without formal education. For every unit (GHS 1000) increase in GACI, the food security of CFHs also

Table 3 Multiple logistic regression results on the determinants of food security scores in cocoa households in the Forest-Savannah Transition Zone of Ghana $(n=236)$

\begin{tabular}{|c|c|c|c|c|c|c|}
\hline \multirow[t]{2}{*}{ Explanatory variables } & \multicolumn{2}{|l|}{ Unstandardised } & \multicolumn{2}{|l|}{ Standardised } & \multicolumn{2}{|c|}{$95 \%$ Cl_B } \\
\hline & Coefficients (B) & S.E_B & Coefficients & Sig & Upper & Lower \\
\hline SEX & 0.34 & 0.546 & 0.04 & 0.534 & -0.735 & 1.415 \\
\hline AGE & -0.013 & 0.018 & -0.063 & 0.463 & -0.049 & 0.022 \\
\hline EDU & $-0.965^{* *}$ & 0.42 & $-0.158^{* *}$ & 0.023 & -1.794 & -0.137 \\
\hline FEX & -0.007 & 0.018 & -0.033 & 0.703 & -0.042 & 0.029 \\
\hline COEX & 0.019 & 0.028 & 0.051 & 0.496 & -0.036 & 0.075 \\
\hline SIZE & -0.054 & 0.055 & -0.068 & 0.329 & -0.162 & 0.055 \\
\hline$L A B$ & 0.099 & 0.099 & 0.071 & 0.318 & -0.096 & 0.294 \\
\hline LAND & $-0.162^{*}$ & 0.09 & $-0.131^{*}$ & 0.073 & -0.338 & 0.015 \\
\hline LIVE & -0.569 & 0.394 & -0.094 & 0.15 & -1.345 & 0.207 \\
\hline $\mathrm{GACl}$ & $-0.038^{* *}$ & 0.019 & $-0.153^{* *}$ & 0.042 & -0.075 & -0.001 \\
\hline CINC & 0.009 & 0.044 & 0.015 & 0.842 & -0.079 & 0.096 \\
\hline OFF & 0.213 & 0.372 & 0.039 & 0.567 & -0.52 & 0.947 \\
\hline EXT & 0.162 & 0.397 & 0.026 & 0.683 & -0.62 & 0.945 \\
\hline CRED & 0.242 & 0.438 & 0.034 & 0.58 & -0.62 & 1.105 \\
\hline CASHEW & $-1.569^{* * *}$ & 0.381 & $-0.283^{* * *}$ & 0 & -2.32 & -0.817 \\
\hline DISP & -0.439 & 0.379 & -0.078 & 0.248 & -1.185 & 0.307 \\
\hline Constant & 6.402 & 1.128 & & 0 & 4.178 & 8.625 \\
\hline \multicolumn{7}{|c|}{ Goodness of Fit and Model Performance Statistics } \\
\hline \multicolumn{3}{|l|}{ Number of Observations } & & & & 236 \\
\hline \multicolumn{3}{|l|}{ Durbin-Watson Statistic } & & & & 1.831 \\
\hline \multicolumn{3}{|c|}{ Multiple Correlation Coefficient } & & & & 0.444 \\
\hline \multicolumn{3}{|l|}{$R^{2}$} & & & & 0.197 \\
\hline \multicolumn{3}{|l|}{ Adjusted $R^{2}$} & & & & 0.139 \\
\hline \multicolumn{3}{|l|}{ Statistical Significance } & & & & 0.000026 \\
\hline
\end{tabular}

${ }^{*}$ Significant at $10 \%,{ }^{*}$ Significant at $5 \%,{ }^{* * *}$ Significant at $0.010 \%$ 
increased marginally by -0.038 . In terms of land ownership, a unit increase in the number of separate farmlands owned by a household increased the food security of CFHs by -0.162 , but this result was only significant at $10 \%$ alpha level. The negative sign of the coefficients were because lower scores rather represent higher food security on the USDA scale. The remaining variables (sex, age, farming and cocoa farming experiences, household size, labour size, cocoa income, livestock ownership, displacement of food crops by cocoa, and access to off-farm income, extension and credit) did not influence the food security of CFHs.

The determinants of different categories of food security in CFHs were also assessed using multinomial logistic regression. The multinomial model significantly predicted all the four categories of food security (Likelihood Ratio Chisquare $=80.631, p=0.002)$ and explained $31.30 \%$ of the variation in food security categories (Pseudo $R^{2}=0.313$ ). Six out of the 16 explanatory variables were statistically significant. These comprise of all the four significant predictors of food security scores in the multiple regression model (number of parcels of farmland owned, gross annual income from cocoa, cashew and food crops, education level of the household head, and cashew farming), and two additional variables, i.e., livestock farming and displacement of food crops using cocoa (Table 4).

For every unit increase in the number of parcels of farmland owned by a household, the odds of a $\mathrm{CFH}$ becoming food insecure without hunger compared to food secure decreased by $0.233(p=0.03)$. Similarly, for every unit (GHS 1000) increase in GACI, the odds of food insecure with hunger (moderate) and food insecure with hunger (severe) decreased by $0.084(p=0.012)$ and $0.055(p=0.088)$, respectively. Households headed by people with no formal education also had $3.056(p=0.005)$ and 3.430 times higher odds ( $p=0.006)$ of becoming food insecure without hunger and food insecure with hunger (severe), respectively. Likewise, households without livestock ownership had $1.586(p=0.048)$ and 1.145 times higher odds $(p=0.073)$ of becoming food insecure without hunger and food insecure

Table 4 Multinomial logistic regression results on the determinants of food security in cocoa households in the Forest-Savannah Transition Zone of Ghana $(n=236)$

\begin{tabular}{|c|c|c|c|c|c|c|c|c|c|}
\hline \multirow{3}{*}{$\begin{array}{l}\text { Explanatory } \\
\text { Variables }\end{array}$} & \multicolumn{9}{|c|}{ Outcome Variable: Household Food Security Status ${ }^{a}$} \\
\hline & \multicolumn{3}{|c|}{ Food Insecure Without Hunger } & \multicolumn{3}{|c|}{ Food Insecure With Hunger, Moderate } & \multicolumn{3}{|c|}{ Food Insecure With Hunger, Severe } \\
\hline & $\beta$ & $\operatorname{Exp}(\beta)$ & Sig & $\beta$ & $\operatorname{Exp}(\beta)$ & Sig & $\beta$ & $\operatorname{Exp}(\beta)$ & Sig \\
\hline AGE & -0.003 & 0.997 & 0.893 & -0.013 & 0.988 & 0.515 & -0.026 & 0.974 & 0.266 \\
\hline FEX & -0.008 & 0.992 & 0.727 & 0.002 & 1.002 & 0.918 & 0.016 & 1.016 & 0.494 \\
\hline COEX & 0.022 & 1.023 & 0.524 & -0.005 & 0.995 & 0.877 & 0.008 & 1.008 & 0.817 \\
\hline SIZE & -0.023 & 0.977 & 0.727 & -0.003 & 0.997 & 0.955 & -0.026 & 0.974 & 0.741 \\
\hline LAB & 0.062 & 1.064 & 0.613 & 0.078 & 1.082 & 0.488 & 0.202 & 1.224 & 0.115 \\
\hline LAND & $-0.266^{* *}$ & 0.767 & 0.030 & -0.103 & 0.902 & 0.337 & -0.159 & 0.853 & 0.243 \\
\hline $\mathrm{GACl}$ & -0.012 & 0.988 & 0.639 & $-0.087^{* *}$ & 0.916 & 0.012 & $-0.056^{*}$ & 0.945 & 0.088 \\
\hline CINC & -0.021 & 0.979 & 0.718 & 0.044 & 1.045 & 0.462 & 0.022 & 1.022 & 0.703 \\
\hline SEX & -0.381 & 0.683 & 0.560 & -0.356 & 0.701 & 0.541 & -0.808 & 0.446 & 0.271 \\
\hline EDU & $1.4^{* * *}$ & 4.056 & 0.005 & 0.280 & 1.322 & 0.569 & $1.488^{* * *}$ & 4.430 & 0.006 \\
\hline LIVE & $0.950^{* *}$ & 2.586 & 0.048 & $0.763^{*}$ & 2.145 & 0.073 & 0.108 & 1.114 & 0.843 \\
\hline OFF & -0.429 & 0.651 & 0.352 & -0.423 & 0.655 & 0.298 & 0.010 & 1.010 & 0.984 \\
\hline EXT & -0.074 & 0.928 & 0.880 & 0.369 & 1.447 & 0.373 & -0.306 & 0.737 & 0.564 \\
\hline CRED & -0.160 & 0.853 & 0.767 & -0.052 & 0.950 & 0.912 & -0.034 & 0.967 & 0.953 \\
\hline CASHEW & 0.691 & 1.996 & 0.149 & $1.209^{* * * *}$ & 3.349 & 0.004 & $1.656^{* * * *}$ & 5.241 & 0.001 \\
\hline DISP & 0.307 & 0.736 & 0.555 & 0.394 & 1.482 & 0.335 & $0.989^{* *}$ & 2.689 & 0.044 \\
\hline
\end{tabular}

Goodness of Fit and Model Performance Statistics

\begin{tabular}{ll}
\hline Number of Observations & 236 \\
-2 Log Likelihood & 532.977 \\
Likelihood Ratio (LR) Chi-square & $80.631^{* * * *}$ \\
Nagelkerke (Pseudo) $R^{2}$ & 0.313
\end{tabular}

${ }^{a}$ Reference category is food secure ${ }^{*}$ Significant at $10 \%,{ }^{* *}$ Significant at $5 \%,{ }^{* * *}$ Significant at $1 \%,{ }^{* * *}$ Significant at $0.5 \%$ 
with hunger (moderate), respectively, compared to those that owned livestock. Interestingly, households that established cocoa on non-food crop lands such as fallow lands had 1.689 times higher odds $(p=0.044)$ of becoming food insecure with hunger (severe) compared to those that used cocoa to displace food crops. As in the multiple regression model, cashew farming was also the most significant predictor of food security categories in the multinomial model. CFHs that had not diversified into cashew farming had $2.349(p=0.004)$ and 4.241 times higher odds $(p=0.001)$ of becoming food insecure with hunger (moderate) and food insecure with hunger (severe), respectively.

\section{Discussion}

The food security implications of cash crop production have been extensively debated in research and policy circles $[38,73]$. This paper contributes to the literature by highlighting the significance of crop diversification and assets in understanding the relationship between cash cropping and household food security. Since the FSTZ is the "breadbasket" of Ghana [55], understanding the food security implications of cash crop farming in the zone could be of significance to food security policies at the national level. At the global level, the paper reaffirms the importance of secured land access and income as recognised by the second Sustainable Development Goal of achieving zero hunger by 2030 [70].

The significantly higher crop income and food security of cocoa households are consistent with the literature that cash crops enhance household food security by increasing incomes $[4,41,68,73]$. Although cash income from cocoa enabled households to purchase food as observed by Hirons et al. [36] in the HFZ of Ghana, the food security advantage of CFHs observed in this study was not directly due to income from cocoa as hypothesised. The multiple and multinomial regression results further confirm that income from cocoa alone was not sufficient enough to positively influence food security. That was probably because returns from cocoa were seasonal [10] and yields were much lower in the FSTZ compared to the HFZ [2]. The food security advantage observed was partly because income from cocoa translated into higher annual crop income by enhancing the financial ability of farmers' to diversify into cashew and expand food crop production. Abdulai et al. [2] accentuate that CFHs in the FSTZ earn only $50 \%$ of their annual income from cocoa and 30\% from other crops, and typically rely on crop diversification to compensate for the low yield of cocoa in the zone. Thus, contrary to empirical evidence from the HFZ that cocoa farming limits food access by shifting income distribution from continuous flows to lump sums [10], CFHs in the FSTZ generally experienced a continuous flow of income from cocoa, food crops, and cashew. This enhanced consumption smoothing during the lean season. Findings are, therefore, consistent with empirical evidence that crop diversification enhances crop income [15] and food security $[6,45]$. Findings are also supported by the literature that cash crops can complement food crop production $[4,66]$.

Although the food insecurity of cocoa farmers in Ghana has largely been blamed on land scarcity for food crops [11], in the context of the FSTZ, cocoa farmers reported sufficient access to land and generally used returns from cocoa to expand food crop production. Sufficient access to land and allocating a portion of land for staple food crop production are, therefore, essential for safeguarding the food security of cash crop households $[59,67]$. The positive relationship between cocoa and food crop production observed is akin to Zambia, where jatropha farmers maintained staple food production by expanding their cropping areas [31]. A similar result was obtained in Malawi, where farmers used income from tobacco to pay for additional labour for maize production [53]. Thus, in a context of sufficient land access, cash cropping is likely to lead to income gains that may enhance the productionbased entitlements of subsistence households. Consequently, CFHs depended on self-produced food even to a greater extent than NCFHs, contrary to previous findings [10] that cocoa farming exposes farmers to higher market risk for staple foods. Besides, the downward trend in food production was mainly blamed on unfavourable climate and was cited by a higher proportion of NCFHs compared to CFHs. The argument that cash crops undermine food crop production is, therefore, generally not supported in the context of reviving cocoa farming in the FSTZ.

The multiple and multinomial regression results further imply that the positive relationship observed between cocoa farming and household food security goes beyond crop income; diversification into cashew, displacement of food crops with cocoa, and socioeconomic factors such as land ownership, livestock ownership, and formal education are additional determining factors. The positive influence of education is consistent with the literature that formal education of the household head enhances food security $[1,8,13$, $45,47,50,80]$. Given that primary education forms the foundations of learning and understanding [69], educated household heads probably had greater capacity to understand and apply essential information $[11,65]$ for improved productivity. The positive finding on land ownership also agrees with previous studies $[9,38,58]$. It is further justified by empirical evidence that land tenure security promotes adoption of sustainable agricultural practices $[49,60]$, which can translate into improved productivity [48] and food security [50]. Another plausible reason is that multiplicity of farmlands allowed households to allocate separate lands to cocoa farming without undermining their production-based entitlements. However, the proportion of land allocated to cocoa 
has been shown to influence food security negatively [10], but that could not be examined due to lack of reliable data on land size. For the same reason, land size was not also factored into our analyses despite empirical evidence that increasing land size influences household food security positively $[8,50]$

The positive influence of GACI on food security observed in this study was probably because higher income translated into greater purchasing power for better quality diet [7], apart from granting CFHs more financial resources to expand food crop production. This result is also backed by empirical evidence that household income increases food security [1, 42, 47]. Our study is, however, limited to crop income due to lack of reliable data on total household income. GACI is still a good indicator of income, considering that crops contribute about $80 \%$ of the household income of cocoa farmers in the study area [2]. The small regression coefficients, however, suggest that the influence of GACI was marginal. A very high amount may be required if households are to rely solely on crop income to enhance food security. As noted earlier, the highly significant result on cashew farming was because farming both cashew and cocoa probably resulted in higher and a continuous flow of crop income, thereby enabling households to smoothing consumption, especially during the lean season. This is similar to the case of coffee in Ethiopia [41], where a continuous flow of income enhanced food security by enabling farmers to sustain consumption during the lean season.

While livestock ownership and displacement of food crops by cocoa did not significantly influence the food security scores of CFHs in the multiple regression model, they significantly predicted various categories of food insecurity in the multinomial model. The positive influence of lack of livestock ownership on food insecurity is supported by empirical evidence that livestock improves the nutritional outcomes and food security of households [50,74]. Several other authors corroborate that livestock improves dietary diversity [26, 39] serves as saving and capital investment in areas of limited financial services [27] and provides additional income to enhance the purchasing power of households [50]. Accordingly, livestock production was prioritised by the Ghana Climate-Smart Agriculture and Food Security Action Plan (2015-2020) as a climate-smart and food security strategy for the FSTZ [22]. Contrary to our hypothesis, the multinomial model further implies that households that used cocoa to directly displace food crops (DHs) were rather less likely to experience food insecurity compared to households that established cocoa on non-food croplands (NDHs). While this finding may seem counterintuitive, it appears the practice of using cocoa to directly displace food crops in the study area is an indication of better access to land and self-produced food at the household level, and hence, less associated with household food insecurity. The survey data corroborates that the average number of farmlands owned by DHs
$(2.77 \pm 2.33)$ was above the average for all cocoa households $(2.61 \pm 2.21)$, while that of NDHs $(2.35 \pm 1.98)$ was below the average. In addition, $34.23 \%$ of DHs reported an upward trend in food production in the last 10 years (2007-2017); a percentage which exceeds that of all cocoa households (27.50\%) and NDHs (16.48\%). For the same period, the vast majority of NDHs (76.92\%) reported a downward trend in food production but a lower proportion of DHs (57.72\%) did so. Thus, in the context of sufficient access to land and selfproduced food, using cash crops to displace food crops could probably lower food insecurity risks by enhancing optimum balance between production-based and trade-based entitlements.

\section{Conclusions}

Findings indicate positive relationships between the revival of cocoa farming, household crop income and food security, due to complementarities between cocoa, food crop and cashew production. However, income from cocoa alone is not high enough and widely distributed to guarantee food security. Reinvesting the returns from cocoa in cashew and food crops minimises market dependency for food staples, enhances annual crop income, ensures a continuous flow of income, and, therefore, seems to be a more reliable pathway to enhancing food security than merely depending on the income to buy food. This implies that a complete transition from food crops to cocoa could be detrimental to household food security. A semi-subsistence system that ensures optimum combination of cash and food crops is, therefore, recommended, but this may require sufficient access to land.

The positive relationship between cocoa farming and food security goes beyond annual crop income; diversification into cashew, displacement of food crops with cocoa, and socioeconomic factors such as land ownership, livestock ownership, and formal education are additional determining factors. This highlights the need for a context-specific approach in resolving the age-old debate on cash crops and food security. Based on the findings, it would be pragmatic to mainstream crop diversification (cashew and food crops) and livestock farming into food security interventions for subsistence households transitioning towards cocoa farming. There may also be some merit in incorporating adult education and land acquisition grants into food security policies and programmes for vulnerable households. In the long term, sponsoring a household to buy at least one farmland (of locally appropriate size) and the household head to complete a minimum of primary education (or acquire an equivalent level of literacy) could enhance the food security of vulnerable CFHs. Additional research is, however, needed on how land size and the proportion of land allocated to cocoa, cashew and food crops may influence the income and food security of CFHs. 


\section{Appendix 1. Questionnaire}

My name is

\section{Informed Consent}

. I invite you to respond to a survey on cash crops and food security in this area. Whatever information you provide would be treated as confidential and you would not be named in any report. The survey is estimated to last for less than one hour. Do you voluntarily agree to response to this survey? Yes [ ] No [ ]

\section{SECTION A. PERSONAL DATA OF HOUSEHOLD HEAD}

I would begin by asking about the head of your household. By household, I mean you and all the people (including children if any) with whom you eat from the same pot; share the same accommodation and other resources like money, land and equipment.

(1) Name of household head?

$\begin{array}{ll}\text { (2) Sex of household head: 1. Male [ ] 2. Female [ ] } & \text { 2 }\end{array}$

(3) Age of household head: Years

(4) Highest level of academic schooling completed by household head:

1. None [ ] 2. Primary [ ] 3. JHS/Form4 [ ] 4. SHS/O or A Level [ ] 5. Tertiary [ ]

(5) Number of years household head has been engaged in farming:

(6) Number of years household head has been farming cocoa__ (Put zero if none)

\section{SECTION B. CROP FARMING STRATEGIES}

I would now like to ask you about the crop farming strategies of your household.

(1) Is your household engaged in cocoa farming in this area? 1. Yes [ ] 2. No [ ]

(2) If yes, what was the land-use type of the land(s) before using it for cocoa (tick all that apply)? 1. Food

cropland [ ] 2. Fallow land [ ] 3. Secondary forest [ ] 4. Tree plantation [ ]

(3) Was any of the cocoa farms established on food cropland in the last 20 years (1997-2017)?

1. Yes [ ] 2. No [ ]

(4) If farming cocoa, was some or all of the land (currently used for cocoa) previously rented out to food crop farmers? 1. Yes[ ] 2.No[ ]

$\begin{array}{lll}\text { (5) Is your household farming cashew? 1. Yes [ ] } & \text { 2. No[ ] }\end{array}$

(6) Please mention all the crops your household depend on for income.

(7) What is your households' grossincome from the above crops in the last 12 months? GH $\phi$

To Enumerator: Estimate income from each crop using the quantity sold and the average unit price, and sum up the figures.

(8) From experience, what are the income and food security merits, if any, of maintaining a diversified portfolio of cocoa, cashew and food crops?

\section{SECTION C. LIVELIHOOD ASSETS}

In this section, I would ask about some of the resources owned or services accessed by your household.

(1)How many separate parcels of farmland does your household own?

(2) Does your household own fallow land? 1.Yes[ ] 2.No[ ]

(3) What is the size of your household?

(4)How many people in your household contribute farm labour?

(5)Has your household accessed extension service in the last 12 months?1. Yes [ ] 2.No [ ]

(6) Does your household own livestock? 1. Yes[ ] 2.No [ ]

(7)Is your household having any other livelihood(s) apart from farming? 1. Yes [ ] 2. No [ ]

(8) Has any member of your household (including you) accessed credit (cash or farm inputs) in the last three $\begin{array}{ll}\text { years? 1. Yes [ ] } & \text { 2. No [ ] }\end{array}$ 


\section{SECTION D. FOOD SECURITY ASSESMENT}

The next set of questions are going to be about the food consumed by your household in the last 12 months, and whether you were able to afford the food you needed.

To Enumerator: In the case of single adult households, use "I" instead of "We"; "My" instead of "Our"; and "You" instead of "your household". In a rare case where the respondent doesn't know or refuses to answer a particular question, select "DK or $R$ ".

Stage 1: Questions 1-5 --ask all households:

Now I'm going to read to you several statements that people have made about their food situation. For these statements, please tell me whether the statement was often true, sometimes true, or never true for your household in the last 12 months, that is, since last (name of current month).

(1) "We worried whether our food would run out before we got money to buy more." Was that often true, sometimes true, or never true for your household in the last 12 months?
1. Often true [ ]
2. Sometimes true [ ]
3. Never true [ ]
4. DK or R [ ]

(2) "The food that we bought just didn't last, and we didn't have money to get more." Was that often, sometimes, or never true for your household in the last 12 months?
1. Often true [ ]
2. Sometimes true [ ]
3. Never true [ ]
4. DK or R [ ]

(3) "We couldn't afford to eat balanced meals." Was that often, sometimes, or never true for your household in the last 12 months?
1. Often true [ ]
2. Sometimes true [ ]
3. Never true [ ]
4. DK or R [ ]

To Enumerator: If this household has at least one child, ask Questions 4 and 5; otherwise skip to the next section (1st Level Screen).

(4) "We relied on only a few kinds of low-cost food to feed our child/children because we were running out of money to buy food". Was that often, sometimes, or never true for your household in the last 12 months?
1. Often true [
2. Sometimes true [
3. Never true [ ]
4. DK or R [ ]

(5) "We couldn't feed our child/children a balanced meal, because we couldn't afford that." Was that often, sometimes, or never true for your household in the last 12 months?
1. Often true [ ]
2. Sometimes true [ ]
3. Never true [ ]
4. DK or R [ ]
1st-Level Screen
To Enumerator: IF AFFIRMATIVE RESPONSE (i.e., "often true" or "sometimes true") to ANY ONE of Questions 1-5, then continue to the next stage (i.e. Stage 2); otherwise, skip to Question 16.

Stage 2: Questions 6-10 --ask households passing the 1st -Level Screen

To Enumerator: If this household has at least one child, ask Question 6; otherwise skip to Question 7.

(6) $\quad$ "Our child was/children were not eating enough because we just couldn't afford enough food." Was that often, sometimes, or never true for your household in the last 12 months?
1. Often true [
2. Sometimes true [ ]
3. Never true [ ]
4. DK or R [ ]

(7) In the last 12 months, since last (name of current month), did you or other adults in your household ever cut the size of your meals or skip meals because there wasn't enough money for food?
1. Yes [ ]
2. No [ ]
3. DK or R [ ]

7a) [IF YES ABOVE, ASK] How often did this happen---almost every month, some months but not every month, or in only 1 or 2 months?
1. Almost every month [ ]
2. Some months but not every month [ ]
3.Only 1 or 2 months [ ]
4.DK or R [ ]

(8) In the last 12 months, did you ever eat less than you felt you should because there wasn't enough money to buy food? 1 . Yes [ ] 3 2. No [ ] $\quad 3$. DK or R [ ] 
(9) In the last 12 months were you ever hungry but didn't eat because you couldn't afford enough food?
1. Yes [ ]
2. No [ ]
3. DK or R [ ]

(10) In the last 12 months, did you lose weight because you didn't have enough money for food?
1. Yes [ ]
2. No [ ]
3. DK or R [ ]

2nd-Level Screen

To Enumerator: IF AFFIRMATIVE RESPONSE (i.e., "yes' or "often true" or "sometimes true") to ANY ONE of Questions 6 through 10, then continue to Stage 3; otherwise, skip to Question 16.

Stage 3: Questions 11-15 --ask households passing the 2nd -Level Screen

(11) In the last 12 months did you or other adults in your household ever not eat for a whole day because there wasn't enough money for food?
1. Yes [ ]
2. No [ ]
3. DK or R [ ]

11a) [IF YES ABOVE, ASK] How often did this happen---almost every month, some months but not every month, or in only 1 or 2 months?
1. Almost every month [ ]
2. Some months but not every month [ ]
3.Only 1 or 2 months [ ]
4.DK or R [ ]

To Enumerator: If this household has at least one child, ask Questions 12-15; otherwise, skip to Question 16.

(12) In the last 12 months, since (current month) of last year, did you ever cut the size of your child's/any of the children's meals because there wasn't enough money for food?
1. Yes [ ]
2. No [ ]
3. DK or R [ ]

(13) In the last 12 months did your child/any of your children ever skip meals because there wasn't enough money for food? 1. Yes [ ] 2. No [ ] 3. DK or R [ ]

13a) [IF YES ABOVE ASK] How often did this happen---almost every month, some months but not every month, or in only 1 or 2 months?
1. Almost every month [ ]
2. Some months but not every month [ ]
3.Only 1 or 2 months [ ]
4.DK or R [ ]

(14) In the last 12 months was your child/were the children ever hungry but you just couldn't afford more
food? 1. Yes [ ]
2. No [ ]
3. DK or R [ ]

(15) In the last 12 months did your child/any of the children ever not eat for a whole day because there wasn't enough money for food? 1. Yes [ ] 2. No [ ] 3. DK or R [ ]

(16) Does your household experience food shortage in certain months of the year?
1. Yes
2. No []

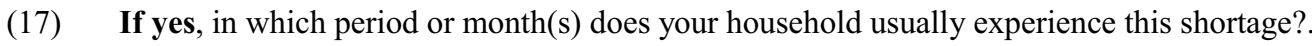

(18) What has been the general trend in your household's food production in the last ten years (2007-2017)?
1. Decreasing [ ]
2. No noticeable change [
3.Increasing [ ]

(19) What do you think mainly accounts for the above trend in your household's food production?

(20) What is your household's major source of staple foods?
1. Self-production [ ]
2. Market [ ]
3. Self-production and market [ ]

END OF SURVEY!

Thank you for completing this survey. 


\section{Acknowledgements}

We appreciate the Association of African Universities (AAU) for financing this study through the Small Grants for Dissertations and Theses Programme. We also thank the farmers in the Wenchi, Techiman North, Mampong and Offinso North districts/municipalities for providing substantial information for this study.

\section{Authors' contributions}

All authors contributed to the study conception and design. IH performed the data collection and analysis, and wrote the first draft of the manuscript. All authors commented on previous versions of the manuscript. All authors read and approved the final manuscript.

\section{Funding}

This study was funded by the Association of African Universities (AAU) through the Small Grants for Dissertations and Theses Programme.

\section{Availability of data and materials}

The data sets used and/or analysed during the current study are available from the corresponding author on reasonable request.

\section{Declarations}

\section{Ethics approval and consent to participate}

Not applicable.

\section{Consent for publication}

Not applicable.

\section{Competing interests}

The authors declare that they have no competing interests.

Received: 25 February 2021 Accepted: 6 January 2022

Published online: 12 February 2022

\section{References}

1. Abbasi N, Ghoochani OM, Ghanian M, Miranda K. Assessment of households' food Insecurity through use of a USDA Questionnaire. Adv Plants Agric Res. 2016. https://doi.org/10.15406/apar.2016.04.00155.

2. Abdulai I, Jassogne L, Graefe S, Asare R, Van Asten P, LaĖderach P. Characterization of cocoa production, income diversification and shade tree management along a climate gradient in Ghana. PLoS ONE. 2018;13:4. https://doi.org/10.1371/journal.pone.0195777.

3. Abdu-Raheem KA, Worth SH. Household food security in South Africa: Evaluating extension's paradigms relative to the current food security and development goals. South Afr J Agric Exten. 2011;39(2):91-103.

4. Achterbosch TJ, van Berkum S, Meijerin G.W. Cash crops and food security: Contributions to income, livelihood risk and agriculural innovation. Wageningen UR (University \& Research Centre), LEl Report 2014-015, 2014; ISBN 978-90-8615-673-3.

5. Adjei-Nsiah S, Kermah M. Climate change and shift in cropping system: from cocoa to maize based cropping system in the Wenchi area of Ghana. Br J Environ Clim Change. 2012;2(2):137-52.

6. Adjimoti GO, Kwadzo GT. Crop diversification and household food security status: evidence from rural Benin. Agricul and Food Security. 2018;7:82. https://doi.org/10.1186/s40066-018-0233-x.

7. Adom PK. Determinants of food availability and access in Ghana: what can we learn beyond the regression results? Stud Agric Econ. 2014;116:153-64. https://doi.org/10.7896/j.142.

8. Agidew AA, Singh KN. Determinants of food security in the rural farm households in South Wollo Zone of Ethiopia: the case of the Teleyayen sub-watershed. Agric Food Econ. 2018;6:10. https://doi.org/10.1186/s40100-018-0106-4.

9. Alpízar F, Saborío-Rodríguez M, Martínez-Rodríguez MR, et al. Determinants of food insecurity among smallholder farmer households in Central America: Recurrent versus extreme weather-driven events. Reg Environ Change. 2020;20:22. https://doi.org/10.1007/s10113-020-01592-y.

10. Anderman TL, Remans R, Wood SA, DeRosa K, DeFries RS. Synergies and tradeoffs between cash crop production and food security: A case study in rural Ghana. Food Security. 2014;6(4):541-54. https://doi.org/10.1007/ s12571-014-0360-6.

11. Asamoah M, Owusu Ansah $F$, Anchirinh V, et al. Insight into the Standard of Living of Ghanaian Cocoa Farmers. Greener J Agric Sci. 2013;3(5):363-70.

12. Asante WA, Acheampong E, Kyereh E, Kyereh B. Farmers' perception on climate change; its manifestations in smallholder cocoa systems and shifts in cropping pattern in the forest-savannah transitional zone of Ghana. Land use policy. 2017;66:374-81. https://doi.org/10.1016/j.landu sepol.2017.05.010.

13. Assefa TS. Household level food insecurity assessment: Evidence from panel data Ethiopia. Sci Afr. 2020. https://doi.org/10.1016/j.sciaf.2019.e00262.

14. Awotide, B.A., Abdoulaye, T., Alene, A. and Manyong, V.M. (2015) Impact of Access to Credit on Agricultural Productivity: Evidence from Smallholder Cassava Farmers in Nigeria. In a paper prepared for oral presentation at the International Conference of Agricultural Economists (ICAE), $9^{\text {th }}-14^{\text {th }}$ August 2015. Milan, Italy.

15. Bellon MR, Kotu BH, Azzarri C, Caracciolo F. To diversify or not to diversify, that is the question. Pursuing agricultural development for smallholder farmers in marginal areas of Ghana. World Dev. 2020. https://doi.org/10. 1016/j.worlddev.2019.104682.

16. Belsky J, Siebert S. Cultivating cacao: implications of sun-grown cacao on local food security and environmental sustainability. Agric Hum Values. 2003:20:277-85.

17. Bickel, G, Nord, M., Price, C., Hamilton, W. and Cook, J. (2000) Guide to Measuring Household Food Security, Revised 2000. U.S. Department of Agriculture, Food and Nutrition Service, Alexandria VA.

18. Brinkman M, Levin-Koopman J, Wicke B, Shutes L, Kuiper M, Faaij A, Hilst FVD. The distribution of food security impacts of biofuels, a Ghana case study. Biomass Bioenerg. 2020;141: 105695. https://doi.org/10.1016/j. biombioe.2020.105695.

19. Chege J, Lemba J, Semenye P. Influence of agricultural extension on household food security status among the smallholder farmers. Adv Res. 2018;14:1-9. https://doi.org/10.9734/AIR/2018/39267.

20. Cochran, W.G. (1977) Sampling techniques. (3rd.). In Bartlett, J.E., Kotrlik, J.W., and Higgins, C.C. (2001) Organizational Research: Determining appropriate sample size in survey research. Information Technology, Learning, and Performance Journal 19(1), 43-50pp

21. Cushion E, Whiteman A, Dieterle G. Bioenergy development: Issues and impacts for poverty and natural resource management. Washington, DC: The World Bank; 2010.

22. Essegbey, G.O., Nutsukpo, D., Karbo, N. and Zougmoré, R. (2015) National Climate-Smart Agriculture and Food Security Action Plan of Ghana (2016-2020). Working Paper No. 139: CGIAR Research Program on Climate Change, Agriculture and Food Security (CCAFS): Copenhagen, Denmark.

23. Etea BG, Zhou D, Abebe KA, Sedebo DA. Household income diversification and food security: evidence from rural and semi-urban areas in Ethiopia. Sustainability. 2019;11:12. https://doi.org/10.3390/su11123232.

24. FAO (undated) 'Country Pasture/Forage Profiles: Ghana' FAO, Rome.

25. FAO (1996) Declaration on world food security. World Food Summit, FAO, Rome.

26. FAO, Wfp and IFAD, The State of Food Insecurity in the World 2012. Rome: FAO; 2012.

27. FAO, IFAD, UNICEF, WFP and WHO (2018) The State of Food Security and Nutrition in the World 2018. Building climate resilience for food security and nutrition. FAO, Rome.

28. Faridi R, Wadood SN. An econometric assessment of household food security in Bangladesh. Bangladesh Dev Stud. 2010;33(3):97-111.

29. Felker-Kantor E, Wood CH. Female-headed households and food insecurity in Brazil. Food Security. 2012;4(4):607-17.

30. Gamborg C, Millar K, Shortall O, Sandoe P. Bioenergy and land use: Framing the ethical debate. J Agric Environ Ethics. 2012;25:909-25. https://doi. org/10.1007/s10806-011-9351-1.

31. German L, Schoneveld GC, Gumbo D. The local social and environmental impacts of smallholder-based biofuel investments in Zambia'. Ecol Soc. 2011;16:4. https://doi.org/10.5751/ES-04280-160412.

32. Govereh J, Jayne TS. Cash cropping and food crop productivity: synergies or tradeoffs? Agric Econ. 2003;28:39-50.

33. Haddad L, Kennedy E, Sullivan J. Choice of indicators for food security and nutrition monitoring. Food Policy. 1994;19(3):329-43. 
34. Hashmiu I. Farming carbon in Ghana's Transition Zone: Rhetoric versus reality. In: Leach M, Scoones I, editors. Carbon Conflicts and Forest Landscapes in Africa. Abingdon, UK: Routledge; 2015. p. 163-79.

35. Hetherington JB, Wiethoelter AK, Negin JM, Mor SM. Livestock ownership, animal source foods and child nutritional outcomes in seven rural village clusters in Sub-Saharan Africa. Agric Food Sec. 2017;6:9. https://doi.org/ 10.1186/s40066-016-0079-z.

36. Hirons M, Robinson E, McDermott C, Morel A, Asare R, Boyd E, Norris K. Understanding poverty in cash-crop agro-forestry systems: evidence from Ghana and Ethiopia. Ecol Econ. 2018;154:31-41.

37. Immink MDC, Alarcon JA. Household income, food availability and commercial crop production by smallholder farmers in Western Highlands of Guatemala. Econ Dev Cult Change. 1993;41(2):319-42.

38. Jarzebski MP, Ahmed A, Boafo YA, et al. Food security impacts of industrial crop production in sub-Saharan Africa: a systematic review of the impact mechanisms. Food Security. 2020;12:105-35. https://doi.org/10.1007/ s12571-019-00988-x.

39. Jodlowski M, Winter-Nelson A, Baylis K, Goldsmith PD. Milk in the Data: food security impacts from a livestock field experiment in Zambia. World Dev. 2016;77:99-114.

40. Jones S, Gibbon P. Developing agricultural markets in Sub-Saharan Africa: Organic cocoa in rural Uganda. J Devel Stud. 2011;47(10):1595-618. https://doi.org/10.1080/00220388.2011.579107.

41. Kuma T, Dereje M, Hirvonen K, Minten B. Cash crops and food Security: Evidence from Ethiopian smallholder coffee producers. J Devel Stud. 2019;55(6):1267-84. https://doi.org/10.1080/00220388.2018.1425396.

42. Kumba JK, Wegulo F, Otieno J. The impact of socio-economic characteristics on cash and food crop production: implications on household food situation in Kisii Central Sub-County Kenya. Dev Country Stud. 2015;5(5):115-22.

43. Läderach, P., Eitzinger, A., Martinez, A. and Castro, N. (2011). Predicting the impact of climate change on the cocoa-growing regions in Ghana and Cote d'Ivoire. Research Report, International Center for Tropical Agriculture (CIAT), Managua, Nicaragua.

44. Maithya JM, Mugivane Fl, Busienei JR, Chimoita E, Babu MI, Nyang'anga, H.T. Are commercial crops displacing food crops and compromising Kenya's food security? Prime J Business Admin Manag. 2015;5(3):1794-7.

45. Mango N, Makate C, Mapemba L, et al. The role of crop diversification in improving household food security in central Malawi. Agric Food Sec. 2018;7:7. https://doi.org/10.1186/s40066-018-0160-x.

46. Mango N, Zamasiya B, Makate C, Nyikahadzoi K, Siziba S. Factors influencing household food security among smallholder farmers in the Mudzi district of Zimbabwe Dev. Southern Africa. 2014;31(4):625-40.

47. Mbolanyi B, Egeru A, Mfitumukiza D. Determinants of household food security in a rangeland area of Uganda. Afr J Rural Dev. 2017;2(2):213-23.

48. Michler JD, Shively GE. Land tenure, tenure security and farm efficiency: Panel evidence from the Philippines. J Agric Econ. 2014;66:155-69.

49. Nkomoki W, Bavorová M, Banout J. Adoption of sustainable agricultural practices and food security threats: effects of land tenure in Zambia. Land Use Policy. 2018;78:532-8.

50. Nkomoki W, Bavorová M, Banout J. Factors associated with household food security in Zambia. Sustainability. 2019;11:9. https://doi.org/10.3390/ su11092715.

51. OECD (Organisation for Economic Co-operation and Development). Managing risk in agriculture: a holistic approach. Paris, France: OECD; 2009

52. Oluyole KA, Oni OA, Omonona BT, Adenegan KO. Food security among cocoa farming households of Ondo State, Nigeria. ARPN J Agric Biol Sci. 2009:4:7-13.

53. Orr A. Green Gold"? Burley tobacco, smallholder agriculture, and poverty alleviation in Malawi. World Development. 2000;28(2):347-63. https://doi. org/10.1016/S0305-750X(99)00127-8).

54. Osei MJ, Aidoo R, Tuffour T. Determinants of household food security in the Sekyere-Afram Plains District of Ghana. Global Adv Res J Agric Sci. 2013;2(1):347-53.

55. Owusu K, Waylen PR. Identification of historic shifts in daily rainfall regime, Wenchi, Ghana". Clim Change. 2013;117:133-47. https://doi.org/ 10.1007/s10584-013-0692-9.

56. Pinstrup-Andersen P. Food security: definition and measurement. Food security. 2009;1(1):5-7.

57. Rhebergen T, Fairhurst T, Zingor S, Whitb AM. Climate, soil and land-use based land suitability evaluation for oil palm production in Ghana. Eur J Agron. 2016;81:1-14.
58. Rockson G, Bennett R, Groenendijk L. Land administration for food security: a research synthesis. Land Use Policy. 2013;32:337-42.

59. Rubhara TT, Mudhara M, Oduniyi OS, Antwi MA. Impacts of cash crop production on household food security for smallholder farmers: A case of Shamva District, Zimbabwe. Agriculture, 2020; 10: 188; https://doi.org/10. 3390/agriculture10050188.

60. Ruf F. The myth of complex cocoa agroforests: the case of Ghana. Hum Ecol. 2011;39(3):373-88.

61. Sani S, Kemaw B. Analysis of households food insecurity and its coping mechanisms in Western Ethiopia. Agric Food Econ. 2019;7:5. https://doi. org/10.1186/s40100-019-0124-x.

62. Santeramo FG. On the composite indicators for food security: Decisions matter! Food Rev Intl. 2015;31(1):63-73.

63. Schroth G, LaËderach P, Martinez-Valle Al, Bunn C. From site-level to regional adaptation planning for tropical commodities: cocoa in West Africa. Mitig Adap Strat Global Change. 2017;22(6):903-27. https://doi. org/10.1007/s11027-016-9707-y.

64. Sen A. Poverty and famines: An essay on entitlement and deprivation. Oxford: Clarendon Press; 1981.

65. Shaikh FM. Determinants of household food security and consumption pattern in rural Sindh: non-separable agriculture household model. IUB J Soc Sci Human. 2007:5(2):18-39.

66. Strasberg PJ, Jayne TS, Yamano T. Effects of agricultural commercialization on food crop input use and productivity in Kenya. Policy Synthesis No. 41, USAID Bureau for Africa, Washington D.C.; 1999.

67. Thanichanon P, Schmidt-Vogt D, Epprecht M, Heinimann A, Wiesmann U. Balancing cash and food: the impacts of agrarian change on rural land use and wellbeing in Northern Laos. PLoS ONE. 2018;13(12):e0209166.

68. Theriault $V$, Tschirley D. How institutions mediate the impact of cash cropping on food intensification: an application to cotton in Sub-Saharan Africa. World Dev. 2014;64:298-310.

69. UNESCO. International Standard Classification of Education (ISCED) 2011. UNESCO Institute for Statistics. Montreal, Canada; 2012.

70. United Nations. Transforming our world: The 2030 Agenda for Sustainable Development. United Nations Resolution A/RES/70/1, United Nations, New York; 2015.

71. Vigneri, M, Kolavalli S. Growth through pricing policy: The case of cocoa in Ghana. Background paper to the UNCTAD-FAO Commodities and Development Report 2017: Commodity markets, economic growth and development. FAO, Rome; 2018.

72. Wessel M, Quist-Wessel PMF. Cocoa production in West Africa: a review and analysis of recent developments. Wageningen J Life Sci. 2015;74(75):1-7.

73. Wiggins, S., Henley, G. and Keats, S. (2015) Competitive or complementary? Industrial crops and food security in sub-Saharan Africa. Overseas Development Institute (ODI) Report, ISSN: 2052-7209, ODI, London.

74. Wodajo HD, Gemeda BA, Kinati W, Mulem AA, Eerdewijk A, Wieland B. Contribution of small ruminants to food security for Ethiopian smallholder farmers. Small Rumin Res. 2020. https://doi.org/10.1016/j.small rumres.2020.106064.

75. Wood B, Nelson C, Kilic T, Murray S. Up in smoke? Agricultural commercialization, rising food prices and stunting in Malawi. Policy Research Working Paper 6650, Poverty and Inequality Team of the Development Research Group, The World Bank, Washington D.C.; 2012.

76. World Bank. Poverty and hunger: Issues and options for food security in developing countries. The World Bank, Washington D.C, USA; 1986.

77. World Bank. Supply Chain Risk Assessment: Cocoa in Ghana. Washington, DC: The World Bank; 2013.

78. Yaro JA. Is deagrarianization real? A study of livelihood activities in rural northern Ghana. J Mod Afr Stud. 2006;44(1):125-56.

79. Zeller M, Sharma M. Many borrow, more save, and all insure: implications for food and micro-finance policy. Food Policy. 2000;25(2):143-67. https:// doi.org/10.1016/S0306-9192(99)00065-2.

80. Zhou AD, Shah T, Ali S, Ahmad W, Din IU, Ilyas A. Factors affecting household food security in rural northern hinterland of Pakistan. J Saudi Soc Agric Sci. 2019;18(2):201-10. https://doi.org/10.1016/j.jssas.2017.05.003.

\section{Publisher's Note}

Springer Nature remains neutral with regard to jurisdictional claims in published maps and institutional affiliations. 